\title{
Effect of Reynolds number and inflow parameters on mean and turbulent flow over complex topography
}

\author{
Ryan Kilpatrick $^{1,3}$, Horia Hangan ${ }^{1,2}$, Kamran Siddiqui ${ }^{1,3}$, Dan Parvu ${ }^{1,2}$, Julia Lange ${ }^{4}$, Jakob Mann $^{4}$, \\ and Jacob Berg ${ }^{4}$ \\ ${ }^{1}$ WindEEE Research Institute, University of Western Ontario, London, Ontario, N6M 0E2, Canada \\ ${ }^{2}$ Department of Civil and Environmental Engineering, University of Western Ontario, London, \\ Ontario, N6A 5B9, Canada \\ ${ }^{3}$ Department of Mechanical and Materials Engineering, University of Western Ontario, London, \\ Ontario, N6A 5B9, Canada \\ ${ }^{4}$ DTU Wind Energy, Technical University of Denmark, Frederiksborgvej 399, 4000 Roskilde, Denmark
}

Correspondence to: Ryan Kilpatrick (rkilpatr@uwo.ca)

Received: 9 May 2016 - Published in Wind Energ. Sci. Discuss.: 23 May 2016

Revised: 27 September 2016 - Accepted: 11 October 2016 - Published: 17 November 2016

\begin{abstract}
A characterization of mean and turbulent flow behaviour over complex topography was conducted using a large-scale $(1: 25)$ model in the WindEEE Dome at Western University. The specific topographic feature considered was the Bolund Hill escarpment facing westerly winds. A total of eight unique inflow conditions were tested in order to isolate the impact of key parameters such as Reynolds number, inflow shear profile, and effective roughness, on flow behaviour over the escarpment.

The results show that the mean flow behaviour was generally not affected by the Reynolds number; however, a slight increase in speed-up over the escarpment was observed for cases with lower inflow roughness. The shape of the inflow wind shear profile also had a minor impact on the mean flow near the escarpment. More significant effects were observed in the turbulent flow behaviour, where the turbulent kinetic energy (TKE) over the escarpment was found be a strong function of inflow roughness and a weak function of the Reynolds number. The local change in the inflow wind shear was found to have the most significant influence on the TKE magnitude, which more closely approximated the full-scale TKE data, a result which had not been previously observed in wind tunnel modelling of this topography.
\end{abstract}

\section{Introduction}

Wind turbines over the last few decades have emerged as a reliable and cost-competitive means of producing clean, renewable electricity. Although typically built on relatively flat terrain such as plains and farmland, wind farms are increasingly being placed in more rugged, or complex, terrain, marked by abrupt changes in elevation (Palma et al., 2008).

These sites often have strong wind resources, yet designing wind farms for these regions involves additional challenges due to the changes imposed by the terrain on the threedimensional structure of the wind, such as speed-up regions, changes to the wind shear profile, large vertical wind veloc- ities, and modification of turbulence characteristics (Walmsley and Taylor, 1996; Botta et al., 1998). As a result, the essential prediction of on-site wind conditions, often estimated from measurements at a limited number of mast locations, also becomes more challenging. The use of linearized models, the current industry standard for wind resource assessment and turbine micro-siting, proven to be very effective in gently sloping terrain, can produce inaccurate results when applied at sites with very complex terrain (Palma et al., 2008; Berg et al., 2011). The use of more advanced modelling techniques such as Reynolds-averaged Navier-Stokes (RANS) and large eddy simulation (LES) have generally proven to be more accurate in complex topographic terrain (e.g. Rasouli 
and Hangan, 2013) compared to field measurements and are making inroads with industry, although they come with the trade-off of higher computational cost (Ayotte, 2008; Ayotte et al., 2010). These advanced models generally require a higher degree of user input and experience, and thus results can be significantly affected by changes to boundary conditions, turbulence closure models, and other parameters, as shown for example in the wide spread of computational fluid dynamics (CFD) results in the Bolund blind comparison exercise (Bechmann et al., 2011).

Thus, a better understanding of the wind regime in complex terrain, from a fundamental fluid dynamics perspective, is critical, given the opportunities for improved overall wind turbine performance including higher annual electricity production and reduced fatigue loading and associated maintenance costs (Peinke et al., 2004; Berg et al., 2011). This improved understanding of the flow behaviour can be used by modellers to select appropriate boundary conditions and turbulence models with greater confidence. One area that is not fully understood, and forms the subject of this study, is the sensitivity of the mean and turbulent response of the flow over complex topography to changes in the inflow conditions.

\subsection{Wind tunnel modelling of flow over topography}

In order to improve computational models, the model results need to be validated against actual flow conditions. Full-scale testing is ideal for this purpose; however, due to the lack of control of inflow conditions and the significant testing cost, time, and effort required, wind tunnel modelling has served as a valuable tool for development and validation of both numerical and analytical models (Ayotte and Hughes, 2004). Provided that certain conditions are met, measurements taken of the flow across a scale model can provide very useful and repeatable representations of full-scale conditions as well as benchmarking for the validation of numerical and analytical models. The controlled environment of the wind tunnel provides a means of isolating the effects of various parameters on the mean and turbulent flow behaviour, which is usually not possible in the field.

There are several examples of wind tunnel experiments conducted on flow over scale models of real topography for the purpose of wind resource assessment and wind turbine siting. These include isolated hill cases such as Askervein Hill (Taylor and Teunissen, 1987), Kettles Hill (Salmon et al., 1988), and more recently Bolund Hill (Berg et al., 2011), as well as highly topographically complex regions with multiple hills and valleys (Chock and Cochran, 2005; Rasouli et al., 2009; McAuliffe and Larose, 2012).

\subsection{Bolund experiment}

The Bolund experiment arose from the need for additional model validation of flow over complex terrain, extending the
Askervein Hill Project of the early 1980s by offering steeper terrain and thus a greater challenge for numerical models to resolve. Bolund Hill is a peninsula located near Roskilde, Denmark, and is characterized by a long upwind open fjord fetch, a steep escarpment, and a long flat section on top of the island. The Bolund topography is geometrically similar to a typical wind turbine site in complex terrain, albeit on a smaller scale, and is well-suited as a test site given its welldefined, undisturbed inflow conditions, neutral atmospheric stratification, and relative absence of thermal and Coriolis effects (Berg et al., 2011). Although Bolund is a small hill, approximately $12 \mathrm{~m}$ high by $75 \mathrm{~m}$ wide and $130 \mathrm{~m}$ long, similarity laws allow for upscaling by 10-30 times under neutral atmospheric stratification.

Studies of the wind flow over Bolund Hill include the original field campaign (Berg et al., 2011), follow-up lidar measurements of the escarpment wake (Lange et al., 2016a), computational and physical modelling of the hill as a part of the blind comparison test (Bechmann et al., 2011), wind tunnel modelling (Yeow et al., 2015), LES modelling (Diebold et al., 2013), and wind tunnel and LES modelling (Conan et al., 2016). During the field campaign, measurements were taken via 35 anemometers on 10 masts, positioned along two main incoming flow directions referred to as line A $\left(239^{\circ}\right)$ and line $\mathrm{B}\left(270^{\circ}\right)$. These were the benchmark measurements against which the results of subsequent modelling efforts have been compared. A detailed diagram of the Bolund topography, with mast positions and flow directions, appears in Berg et al. (2011).

\subsection{Present study: characterization of mean and turbulent flow over Bolund across a range of input conditions}

The present study is focused on the characterization of the flow over Bolund Hill, along line $\mathrm{B}$, in the vicinity of the escarpment, using two physical scale models $(1: 100$ and $1: 25$ ), at Reynolds numbers (based on model hill height and wind speed at hill height) ranging from $4 \times 10^{4}$ to $5 \times 10^{5}$. The main objectives of this study were to isolate and analyse the dependence of the mean and turbulent flow behaviour over the escarpment on various parameters including Reynolds number, inflow wind shear profile, and inflow roughness. The $1: 25$ scale experiments were conducted at the Wind Engineering, Energy, and Environment Research Institute (WindEEE), while the 1:100 scale experiments were conducted at the Boundary Layer Wind Tunnel Laboratory (BLWTL). Both facilities are located at Western University. The two sets of results were then compared with the full-scale measurements and with results from previous studies on Bolund Hill. Particle image velocimetry (PIV) and Cobra probes were used for flow velocity measurements at key locations on the scaled models. 


\section{Experimental setup}

The experimental setup, comprising the wind tunnel facility, the topographic model, instrumentation, and measurement procedure is described in the sections below for both the WindEEE and BLWTL experiments.

\subsection{WindEEE facility}

The WindEEE dome is a unique wind research facility designed to simulate a wide variety of wind flow patterns including rotational (axisymmetric) and boundary layer flows on larger laboratory scales than conventional wind tunnels. A general description of the facility is provided in Hangan (2014). The hexagonal test chamber, with diagonal length of $25 \mathrm{~m}$, is enclosed in a return air chamber of $40 \mathrm{~m}$ diagonal length. The WindEEE test chamber contains 106 fans, whose wind speed and direction can be varied independently to produce the desired flow conditions. The facility can be operated in two distinct modes: multi-fan wind tunnel or axisymmetric mode. The present experiments were conducted exclusively under the former configuration, with only the fans along one wall of the hexagon in operation. The fans are mounted in an array format, i.e. four rows of 15 fans each, for a total of 60 fans. Each of these fans are $0.8 \mathrm{~m}$ in diameter and operate at approximately $25 \mathrm{~m} \mathrm{~s}^{-1}$ at a nominal power of $30 \mathrm{~kW}$. Each fan is equipped with variable speed drive and can be individually controlled to create a customized flow pattern. A contraction section was positioned immediately downwind of the 60-fan wall to improve flow uniformity and increase flow speed across the $5 \mathrm{~m}$ diameter test section (turntable) in the centre of the chamber. A trip and a series of spires were employed downwind of the fan wall, within the contraction section, to enhance turbulence intensity.

In addition to individual fan control, the WindEEE facility also provides the ability to set roughness element position and height, allowing physical simulation of a wide range of incoming atmospheric boundary layer (ABL) flow profiles. There are over 1500 roughness elements in the test chamber, each with a maximum height of $30 \mathrm{~cm}$. The present experiment employed only the roughness element sections in the vicinity of the contraction, upwind of the turntable. Two different roughness element configurations, both with a uniform element height of roughly $7.5 \mathrm{~cm}$, were used for the WindEEE experiment, hereinafter referred to as $\mathrm{RC} 1$ and $\mathrm{RC} 2$. For RC1, all of the roughness elements upwind of the turntable were raised, whereas for $\mathrm{RC} 2$, one block of about 80 elements immediately upwind of the turntable was lowered to the floor, resulting in a lower effective roughness value than that of $\mathrm{RC} 1$.

\subsection{Bolund scale model}

The $1: 25$ scale model of Bolund Hill was produced by computer numeric control (CNC) milling of several large blocks

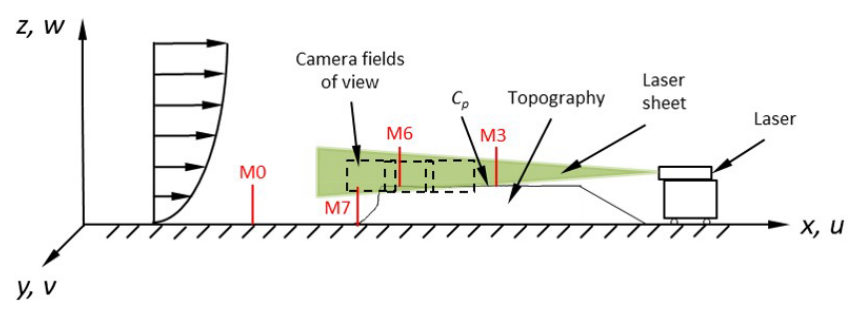

Figure 1. Schematic of WindEEE experimental setup.

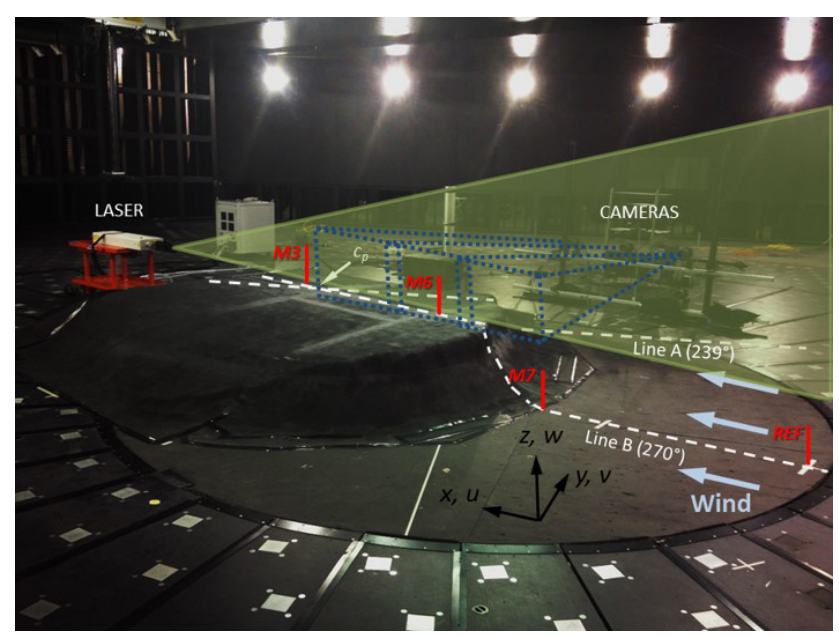

Figure 2. Photograph of the WindEEE experimental setup.

of expanded polystyrene (EPS) according to topographical data of the island. These blocks were then glued together and painted black with latex paint. The overall size of the model was roughly $4.5 \mathrm{~m}$ across, $0.5 \mathrm{~m}$ high, and $3.5 \mathrm{~m}$ long. A solid ramp with slope of roughly $45^{\circ}$ was constructed from EPS and fastened to the downwind edge of the model to provide a smooth transition and reduce unwanted flow separation. The model was positioned in the chamber such that the escarpment edge was roughly $12.4 \mathrm{~m}$ from the 60 -fan wall, and the plane of measurement (along line B) was parallel to the flow direction. A simplified schematic diagram of the WindEEE experimental setup is shown in Fig. 1, while a photograph of the experimental setup is presented in Fig. 2. The centre point of the model, $C_{\mathrm{p}}$, was set as the reference location $(X=0)$, which was also the intersection of lines A and B, as per the full-scale co-ordinate system (see Fig. 2).

\subsection{PIV measurement}

PIV was used to measure the two-dimensional velocity field in a vertical plane above the model, along line $\mathrm{B}$, in the vicinity of the escarpment. The measurement region encompassed a rectangular area extending roughly from $Z=11.4 \mathrm{~m}$ to $Z=25 \mathrm{~m}$ and from $X=-70 \mathrm{~m}$ to $X=-20 \mathrm{~m}$ in the fullscale co-ordinates, where the value $Z=0$ corresponds to sea level. Throughout this work uppercase $Z$ denotes abso- 
lute height above sea level, while lowercase $z$ denotes height measured from the hill surface. Three 12 megapixel cameras (IO Industries Flare 12M125-CL), each with $105 \mathrm{~mm}$ f/2D Nikon AF DC-NIKKOR lenses, were used to capture images. The cameras were positioned in a row parallel to the flow direction, facing the model at a distance of roughly $3.55 \mathrm{~m}$ from the camera lens to the measurement plane, at a height such that the bottom of the camera frame of view was just below the hill surface. Camera resolution was $4096 \times 3072$ pixels, and the corresponding measurement field of view for each camera in the current setup was about $0.78 \mathrm{~m}$ wide by $0.58 \mathrm{~m}$ high. The horizontal positions of the cameras were selected such that the overlap between the adjacent fields of view was at least $10 \%$, ensuring spatial continuity of flow measurements. The overlap between cameras 1 and 2 was $0.167 \mathrm{~m}$ and $0.088 \mathrm{~m}$ between cameras 2 and 3, with camera 1 being the most upwind. Thus the combined measurement area was roughly $2.09 \mathrm{~m}$ wide by $0.58 \mathrm{~m}$ high $(52.3 \mathrm{~m} \times 14.5 \mathrm{~m}$ in fullscale co-ordinates).

A Litron Nano Piv Series dual-cavity Nd:YAG laser with an energy of $425 \mathrm{~mJ}$ pulse $\mathrm{s}^{-1}$, a wavelength of $532 \mathrm{~nm}$, and a beam diameter of $9.5 \mathrm{~mm}$ was used to illuminate the flow field. The laser was positioned directly behind the model, pointing upwind, coincident with line $\mathrm{B}$, with the laser head roughly $0.60 \mathrm{~m}$ off the ground, as shown in Fig. 2. A $50^{\circ}$ cylindrical lens was positioned immediately in front of the laser head to convert the beam into a two-dimensional sheet. The laser was synchronized to the cameras and the frame grabber. In this study, the pulse repetition rate for each laser cavity was set at $9 \mathrm{~Hz}$ resulting in an image acquisition rate of 18 frames per second for each camera or $9 \mathrm{~Hz}$ for each image pair. The images were acquired via IO Industries Coreview software as 8 bit grayscale images in Tagged Image File Format (TIFF) format. PIV data were recorded for $5 \mathrm{~m}$ per test case, providing roughly 2700 image pairs. An Ultratec CLF4460 commercial fog generator, positioned in the dome's upper plenum, was used to seed the test chamber with nontoxic, water-based smoke that served as the tracer. Seeding particle size is estimated to be $\sim 5 \mu \mathrm{m}$ based on the estimation by Ayotte and Hughes (2004) for a commercial fog generator similar to the one used in the present study.

\subsection{Cobra probe measurement}

Cobra probes, manufactured by Turbulent Flow Instrumentation Pty Ltd., are dynamic multi-hole pressure probes for measuring all three components of mean and fluctuating velocities and static pressure. In the present experiment, Cobra probe measurements were taken at an upwind reference location, as well as at a few positions along the hill. A vertical array of eight Cobra probes was used, with spacing between probes ranging from roughly $5 \mathrm{~cm}$ near the bottom of the array to $15 \mathrm{~cm}$ near the top. The total vertical measurement distance was about $60 \mathrm{~cm}$, or $15 \mathrm{~m}$ in full-scale co-ordinates. The upwind reference position was located $4.44 \mathrm{~m}$ upwind

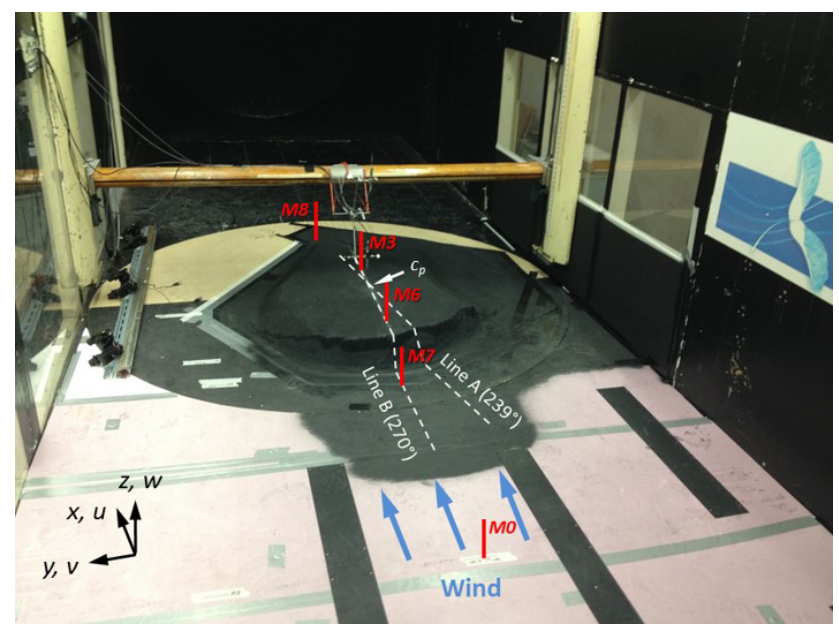

Figure 3. Photograph of the BLWTL experimental setup.

of $C_{\mathrm{p}}$ in the model scale $(2.25 \mathrm{~m}$ upwind of the escarpment leading edge), or $X=-111 \mathrm{~m}$ in the full scale. Although it was initially intended for the Cobra probe position to coincide with the full-scale upwind reference mast M0, located at $X=-180.8 \mathrm{~m}$, this was not possible in the current setup due to the proximity of the model to the contraction opening. However, the selected location was deemed to be sufficient as a reference location given that it was far enough from the fan wall to assume fully mixed flow and far enough from the model to avoid significant slow-down effects. Along the hill, Cobra probe measurements were taken at the escarpment edge $(X=-54.7 \mathrm{~m})$, at M6 $(X=-46.1 \mathrm{~m})$, and at M3 $(X=3.2 \mathrm{~m})$, where values in parenthesis are full-scale co-ordinates. Due to time constraints, Cobra probe measurements at these positions were not taken for each of the PIV test case configurations. The probe array was mounted either on a stationary floor rack or fixed to the overhead rail system and moved to various positions along line B. All Cobra probe measurements were conducted at an acquisition rate of $10000 \mathrm{~Hz}$, an output to file rate of $1250 \mathrm{~Hz}$, and a sampling time of $120 \mathrm{~s}$.

\subsection{BLWTL experimental setup}

The model used for the BLWTL experiments was a $1: 100$ scale model of Bolund Hill, using the same topographical data as the WindEEE model. The BLWTL model was similarly cut from EPS, in two sections, and fastened together. The model was then fixed to the turntable at the centre of the test section and rotated such that the principal flow direction coincided with line B. Figure 3 shows a photograph of the experimental setup with wind direction and mast positions indicated. BLWTL Tunnel 1 is an open circuit type with a length of $33 \mathrm{~m}$ and has a cross section of $2.4 \mathrm{~m}$ (width) $\times 2.15 \mathrm{~m}$ (height) at the test section. In the present setup, three triangular spires, as well as a bar trip were positioned at the far 
upwind end of the tunnel; however, no active roughness elements were used in order to simulate inflow conditions with an ABL profile over a smooth surface. The measurements were conducted at a wind speed of $4.6 \mathrm{~m} \mathrm{~s}^{-1}$, which corresponds to a Reynolds number of approximately $3.6 \times 10^{4}$, using the maximum height of the hill $(0.117 \mathrm{~m}$ in model scale $)$ as the characteristic length.

Cobra probe measurements were conducted along vertical profiles at model-scale positions equivalent to the full-scale co-ordinates of M0, M7, M6, M3, and M8, as well as at the escarpment ( $X=-54.7 \mathrm{~m}$ in full scale). The vertical velocity profile was obtained by using two Cobra probes mounted to the wind tunnel traverse system, and the vertical position was incremented after each sample by $12.7 \mathrm{~mm}$ in model scale $(1.27 \mathrm{~m}$ in full scale) near the floor and $50-100 \mathrm{~mm}(5-10 \mathrm{~m}$ full scale) higher up. The vertical extent of the measurements was about $1.2 \mathrm{~m}$ from the floor (equivalent to $120 \mathrm{~m}$ in full scale). PIV measurements were conducted as well but are not presented here due to a number of issues with data quality.

\section{Data processing}

The methods of data processing, for both PIV and Cobra probe measurements, are described in the following sections.

\subsection{PIV data processing}

PIV instantaneous velocity fields were obtained by crosscorrelating the interrogation regions in the first image of the image pair with the corresponding search regions in the second image. An in-house algorithm implemented in image processing software Heurisko ${ }^{\circledR}$ developed by AEON Verlag $\&$ Studio GmbH \& Co. KG was used for the PIV data processing. The search window and interrogation window sizes were set as 128 and 64 pixels, respectively, while the grid distance was 16 pixels, with $75 \%$ overlap for the interrogation windows. This resulted in a nominal spatial resolution of roughly $3.04 \mathrm{~mm}$ for the velocity fields. Spurious vectors were identified and corrected using a local median test developed by Siddiqui et al. (2001). Subsequently, mean fields were calculated by averaging the respective velocity component (streamwise, $U$, and vertical, $W$, in the present case) at each grid point over the sampling time. The turbulent velocity fields were computed by subtracting the mean velocity from the instantaneous velocity at each grid point in a given velocity field. These two steps were performed using an inhouse code in MATLAB.

PIV statistics were calculated in a manner analogous to Yeow et al. (2015) to enable direct comparison. Mean flow speed, $S$, was calculated using the two mean wind components $U$ and $W$ from the PIV measurement plane (see Fig. 2) as follows:

$S=\left(U^{2}+W^{2}\right)^{1 / 2}$.
Results shown throughout this work are often expressed as a normalized speed-up ratio $S(x, z) / S_{0}(z)$, where $S_{0}(z)$ is the inflow reference speed at the same height. Since the inflow Cobra probe measurements were taken only up to a height of $0.68 \mathrm{~m}$ above the floor and the PIV windows reached a height of about $1 \mathrm{~m}$, extrapolation was carried out according to the following logarithmic law (Manwell et al., 2009):

$U(z) / U\left(z_{\mathrm{r}}\right)=\ln \left(\frac{z}{z_{0}}\right) / \ln \left(\frac{z_{\mathrm{r}}}{z_{0}}\right)$,

where $z_{\mathrm{r}}$ is the reference height. While ideally the inflow profile would have been measured up to the maximum height of the PIV measurement window, this was not feasible with the equipment available at the time of the experiments. Thus, given these limitations, the logarithmic law was selected as the best fit to the measured data. Mean turbulent kinetic energy (TKE), $\bar{k}$, was calculated according to

$\bar{k}=\left(\overline{u^{\prime 2}}+\overline{w^{\prime 2}}\right) / 2$,

where $u^{\prime}$ and $w^{\prime}$ represent the fluctuating velocity vectors. The TKE increment $\Delta \bar{k}$ was obtained by subtracting the inflow reference TKE $\bar{k}_{05}$ at a fixed height of $Z=5 \mathrm{~m}$ in full scale $(0.2 \mathrm{~m}$ in model scale) from the measured TKE at each PIV grid position and normalizing by the square of the inflow reference speed, again consistent with Yeow et al. (2015):

$\Delta \bar{k}=\left[\bar{k}(x, z)-\bar{k}_{05}\right] / S_{0}^{2}(z)$.

Despite efforts to properly align the three cameras, some minor discrepancies were observed in the velocity data recorded by each camera. For mean wind speeds, error between camera frames typically ranged from about $2-4 \%$, with slightly more error in the highly turbulent region close to the escarpment and just above the model surface. To improve the clarity of presentation, a frame stitching algorithm was implemented to smooth the data within the overlap region between camera frames. At each point in the overlapping region, a weighted average of the data at the two overlapping nodes was taken, such that data points closer to one camera or another were weighted more heavily towards that camera's values. The weightings varied linearly from 0.5 for each camera at the centre of the overlap region (equal weighting) to 1 and 0 on one side and 0 and 1 on the other.

\subsection{Cobra probe data processing}

Cobra probe output data are generated by the companion TFI Device Control software and consist of a time history of instantaneous $u, v$, and $w$ component wind speeds, as well as a summary output of the mean wind speeds and Reynolds stresses and pressures. The Cobra probe results presented in this work generally use two-component calculations, where the spanwise wind speed component $v$ is neglected, as per Eqs. (1) and (3), which allows for direct comparison with 
the PIV results, which is analogous to the approach adopted by Yeow et al. (2015) for hot-wire measurements. However, when comparing the WindEEE and BLWTL inflow profiles, measured with Cobra probes, against the full-scale data from upwind reference mast M0, all three wind speed components from the Cobra probe data were used.

\section{Inflow profiles}

Inflow conditions for the various test cases, for both the WindEEE and BLWTL experiments, are described in the sections below.

\subsection{WindEEE fan configuration}

For the present set of experiments, the 60 fans were operated using four different configurations, which were selected in an attempt to match the full-scale incoming wind profile, as well as to produce a range of Reynolds numbers (see Table 1):

a. all fans running at $20 \%$ of the maximum fan rpm

b. all fans running at $30 \%$ of the maximum fan rpm

c. all fans running at $50 \%$ of the maximum fan rpm

d. fans in row 1, 2, and 4 running at $50 \%$ and fans in row 3 at $75 \%$ of the maximum fan rpm; for reference, fan row 1 is at floor level.

The notation for each test case was set based on the inflow wind speed and the inflow surface roughness. That is, each of the four fan configurations are identified by the mean streamwise incoming wind speed at the model escarpment height in metres per second (i.e. U5, U8, U14, U15) and one of two roughness configurations ( $\mathrm{RC} 1$ or $\mathrm{RC} 2$ ), where $\mathrm{RC} 1$ corresponds to higher roughness. For example, case U5RC1 corresponds to the test case conducted at the inflow condition of $5 \mathrm{~m} \mathrm{~s}^{-1}$ wind flowing over higher roughness. These combinations yielded eight unique flow configurations representing the WindEEE PIV test cases described throughout this work, as listed in Table 1.

\subsection{WindEEE inflow parameters}

Cobra probe measurements taken at the upwind reference position were used to determine inflow conditions, with mean speed, TKE, Reynolds shear stress, and integral length scales being of primary interest for the present study. Upwind mean speed $S_{0}$ and TKE $\overline{k_{0}}$ are shown in Fig. 4 along with the fullscale measurements at M0 (Berg et al., 2011). Inflow profiles of Reynolds shear stress and integral length scales are shown in Fig. 5. The Reynolds number was calculated according to

$\operatorname{Re}=\frac{U_{h} h}{v}$, where the characteristic length $h$ is the hill height, $U_{h}$ is the inflow streamwise velocity at $h$, and $v$ is the kinematic viscosity of air. The Reynolds numbers in Table 1 use the model hill height $h=0.468 \mathrm{~m}$. For the test cases with the same fan configuration but different roughness configuration, the Reynolds number was almost identical. Inflow turbulence intensity at hill height $I_{u_{h 0}}$ was approximately 0.13 for all WindEEE test cases. The boundary layer height $\delta$ was taken as the height at which the mean streamwise velocity was equal to $0.99 U_{\infty}$, where $U_{\infty}$ is the free-stream velocity. The ratio of boundary layer height to hill height $\delta / h$ ranged from 3.3 to 3.6 for the WindEEE cases.

For the present study, which focuses mainly on how inflow conditions affect flow behaviour over the escarpment, the means by which the inflow parameters are calculated are important, as there is often some variability depending on the method of calculation. For example, friction velocity $u_{*}$ can be determined using several different methods, which often show considerable differences between them (Weber, 1999). To compare the variability of the resulting normalized inflow profiles for the WindEEE experiment, the friction velocity was calculated using four different methods. For Method 1, friction velocity was calculated according to Eq. (6), as per Weber (1999), using only the longitudinal component of the Reynolds stress vector. This is analogous to the method used by Berg et al. (2011) to calculate friction velocity using data from the inflow reference mast $\mathrm{M} 0$ at a height of $5 \mathrm{~m}$ above sea level in the Bolund field campaign.

$u_{*}=\left(-\overline{u^{\prime} w^{\prime}}\right)^{1 / 2}$

Method 2 adds the spanwise Reynolds stress component (Ly, 1993; Weber, 1999) and always produces a higher value of $u_{*}$ than Method 1. It is similar to the method used in Bechmann et al. (2011) and is given by

$u_{*}=\left[\left(\overline{u^{\prime} w^{\prime}}\right)^{2}+\left(\overline{v^{\prime} w^{\prime}}\right)^{2}\right]^{1 / 4}$.

For Methods 1 and 2, a single reference value $u_{*_{05}}$ was taken as the friction velocity at a reference height of $Z=5 \mathrm{~m}$ in full scale ( $0.2 \mathrm{~m}$ in model scale), consistent with the approach used by Bechmann et al. (2011) and Yeow et al. (2015). In an undisturbed boundary layer profile, the region of constant Reynolds shear stress has been shown to correspond to the equilibrium sub-layer where TKE production balances with the dissipation (Tritton, 1977). For the WindEEE experiments, the three data points closest to the floor for each test case were found to be within this constant shear stress region (see Fig. 5a). The reference height used for Methods 1 and 2, $Z=5 \mathrm{~m}$ in full-scale co-ordinates, falls within this region. For Method 3, effective roughness $z_{0}$ and friction velocity $u_{*}$ were estimated using the standard approach for neutral stability conditions, i.e. by determining the linear line of best fit on a semi-log plot of $\ln (z)$ vs. $U$, where the slope of the line 

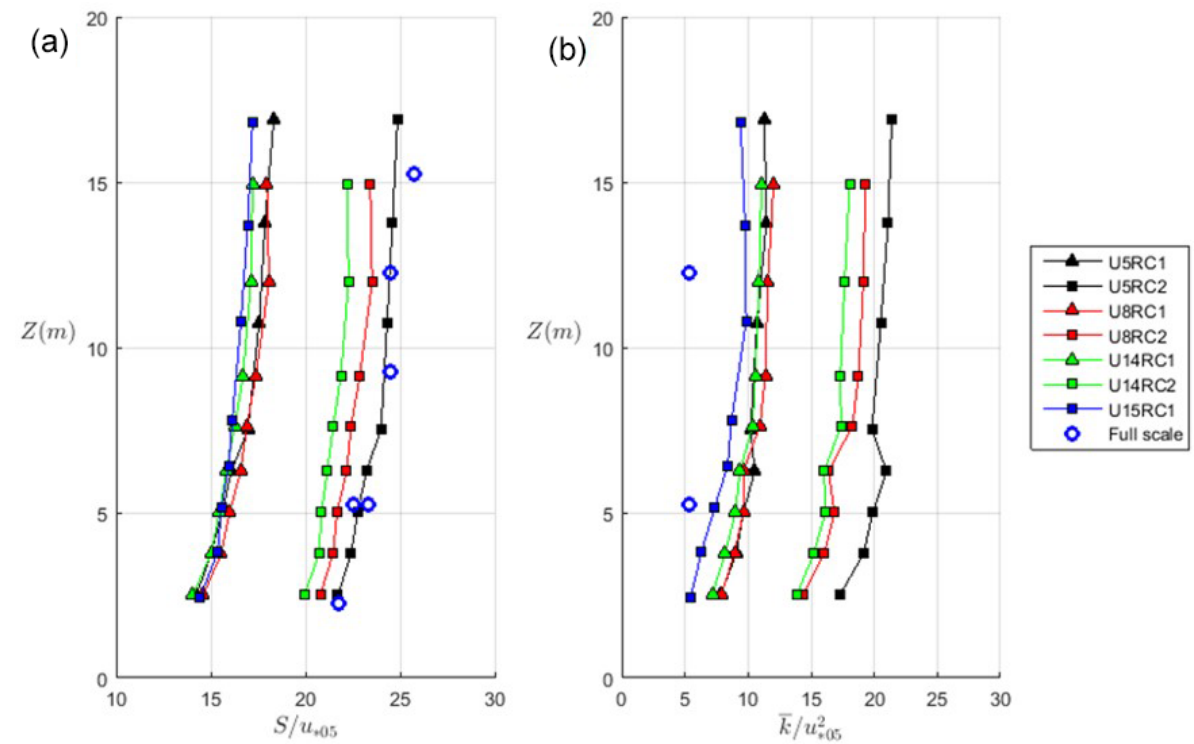

Figure 4. WindEEE inflow profiles of (a) mean flow speed and (b) TKE, normalized by friction velocity obtained using Method 1. $S$ and $\bar{k}$ calculated using all three components of wind speed from Cobra probe measurements. $Z$ co-ordinates shown in full-scale units.
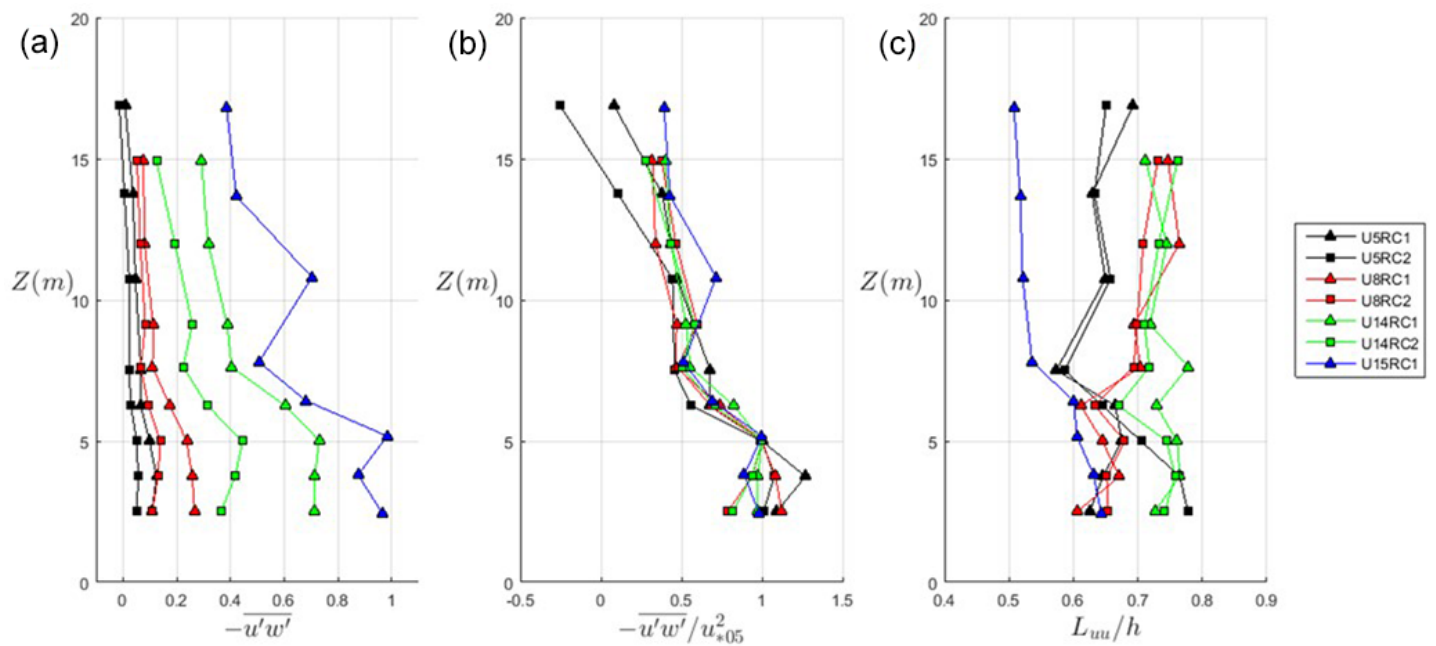

Figure 5. WindEEE inflow profiles: (a) Reynolds shear stress magnitudes, (b) Reynolds shear stress normalized by friction velocity (Method 1), and (c) integral length scales of the streamwise velocity component, normalized by hill height $h$.

is $\kappa / u_{*}$ and the $y$ intercept is $\ln \left(z_{0}\right)$ (Manwell et al., 2009):

$\ln (z)=\left(\frac{\kappa}{u_{*}}\right) U(z)+\ln \left(z_{0}\right)$,

where $z$ is the vertical height above the ground, $U(z)$ is the streamwise wind speed at that height, and the von Karman constant $\kappa$ was considered to be 0.41 . The line of best fit was drawn only through data points residing within the region of constant shear stress. Method 4 follows the approach of Akomah et al. (2011), where $u_{*}$ is considered to be equal to the average of the values of $u_{*}$ values at heights within the region of constant shear stress. The values of $u_{*}$ esti- mated using each of the four methods are presented in Table 1 . As the data show, the difference between the highest and lowest estimate was relatively high, ranging from about 15 to $50 \%$ depending on the test case. The $z_{0}$ values shown in Table 1 were obtained using Method 3 and are presented in full-scale units. The values show a clear distinction between the RC1 cases $\left(z_{0} \sim 10^{-3} \mathrm{~m}\right)$ and RC2 cases $\left(z_{0} \sim 10^{-6} \mathrm{~m}\right)$. The RC1 cases fell within the fully aerodynamically rough regime, where friction Reynolds number $u_{*} z_{0} v^{-1} \gg 1$ (see Table 1), as described by Bowen (2003). Thus no dependence of $z_{0}$ on $u_{*}$ is expected for these cases. The RC 2 cases, however, fell within the aerodynamically smooth regime, where 
Table 1. Inflow parameters for WindEEE and BLWTL test cases.

\begin{tabular}{|c|c|c|c|c|c|c|c|c|c|}
\hline Parameter & U5RC1 & $\mathrm{U} 5 \mathrm{RC} 2$ & U8RC1 & U8RC2 & U14RC1 & $\mathrm{U} 14 \mathrm{RC} 2$ & $\mathrm{U} 15 \mathrm{RC} 1$ & BLWTL & Full scale \\
\hline Fan config. & $\begin{array}{l}\text { All fans } \\
20 \%\end{array}$ & $\begin{array}{l}\text { All fans } \\
20 \%\end{array}$ & $\begin{array}{l}\text { All fans } \\
30 \%\end{array}$ & $\begin{array}{l}\text { All fans } \\
30 \%\end{array}$ & $\begin{array}{l}\text { All fans } \\
50 \%\end{array}$ & $\begin{array}{l}\text { All fans } \\
50 \%\end{array}$ & $\begin{array}{c}\text { Rows } 1,2,4: 50 \% \\
\text { Row 3: } 75 \%\end{array}$ & Single fan & - \\
\hline$U_{h}\left(\mathrm{~ms}^{-1}\right)$ & 5.42 & 5.49 & 8.70 & 8.57 & 14.60 & 14.69 & 15.60 & 4.65 & $5.43-13.0$ \\
\hline$R e_{h}$ & $1.70 \times 10^{5}$ & $1.72 \times 10^{5}$ & $2.72 \times 10^{5}$ & $2.68 \times 10^{5}$ & $4.57 \times 10^{5}$ & $4.60 \times 10^{5}$ & $5.21 \times 10^{5}$ & $3.63 \times 10^{4}$ & $4.25-10.2 \times 10^{6}$ \\
\hline$z_{0}(\mathrm{~m})$ & $1.84 \times 10^{-3}$ & $1.96 \times 10^{-6}$ & $1.98 \times 10^{-3}$ & $4.12 \times 10^{-7}$ & $2.72 \times 10^{-3}$ & $2.29 \times 10^{-6}$ & $2.87 \times 10^{-4}$ & $1.27 \times 10^{-4}$ & $6 \times 10^{-4}$ \\
\hline $\begin{array}{l}u_{* 05}\left(\mathrm{~ms} \mathrm{~s}^{-1}\right) \\
\text { Method } 1\end{array}$ & 0.314 & 0.229 & 0.488 & 0.373 & 0.856 & 0.668 & 0.992 & 0.164 & 0.47 \\
\hline $\begin{array}{l}u_{* 05}\left(\mathrm{~ms} \mathrm{~s}^{-1}\right) \\
\text { Method } 2\end{array}$ & 0.326 & 0.252 & 0.489 & 0.415 & 0.869 & 0.361 & 1.070 & 0.165 & - \\
\hline $\begin{array}{l}u_{*}\left(\mathrm{~ms} \mathrm{~s}^{-1}\right) \\
\text { Method } 3\end{array}$ & 0.254 & 0.145 & 0.409 & 0.203 & 0.723 & 0.392 & 0.650 & 0.164 & - \\
\hline $\begin{array}{l}u_{*}\left(\mathrm{~ms} \mathrm{~s}^{-1}\right) \\
\text { Method } 4\end{array}$ & 0.333 & 0.231 & 0.505 & 0.355 & 0.848 & 0.640 & 0.970 & 0.186 & - \\
\hline$u_{*} z_{0} v^{-1}$ & 37.1 & 0.03 & 62.1 & 0.01 & 149.5 & 0.10 & 18.3 & 1.34 & 18 \\
\hline$I_{u h 0}$ & 0.132 & 0.127 & 0.131 & 0.131 & 0.130 & 0.126 & 0.137 & 0.096 & 0.12 \\
\hline$\delta / h$ & 3.58 & 3.37 & 3.62 & 3.37 & 3.58 & 3.28 & 3.45 & 10.6 & - \\
\hline
\end{tabular}

Roughness lengths shown in full scale. The inflow profile for case U15RC2 was not measured due to an oversight, and as a result the U15RC2 PIV results were normalized against the U15RC1 inflow data.

$u_{*} z_{0} v^{-1}<0.2$; therefore, a dependence of $z_{0}$ on $u_{*}$ is expected. Values of $u_{*} z_{0} v^{-1}$ for each test case are indicated in Table 1. The full-scale roughness measured at mast M0 was $z_{0}=3 \times 10^{-4}$ (Berg et al., 2011), so the U15RC1 case shows the closest match among the WindEEE test cases.

\subsection{Comparison between inflow profiles}

When normalized by $u_{*_{05}}$ (Method 1 ), a clear separation is observed between the profiles with higher roughness (RC1) and those with lower roughness (RC2), with the RC2 group having higher normalized mean wind speed as well as TKE (see Fig. 4). Comparison of the inflow mean speeds for the test cases with the full-scale data shows that all model-scale values are lower than the full-scale wind speeds, with the exception of U5RC2, whereas the normalized TKE profiles are all higher than the full-scale profile, illustrating the inherent difficulty in matching both the mean wind speed and TKE profiles with the full-scale values. The shape of the TKE profiles is in contrast to the wind tunnel experiment conducted by Yeow et al. (2015), whose normalized TKE inflow profiles were lower than the full-scale values and decreased with height. Most of the WindEEE normalized TKE profiles are relatively vertical between $z=5 \mathrm{~m}$ and $z=12 \mathrm{~m}$, which is consistent with the full-scale data, although having only two full-scale data points available from the reference mast M0 in the field campaign, none of which were above a height of $12 \mathrm{~m}$ (i.e. just above escarpment height), is a limiting factor in determining whether a good match to the full-scale conditions has been achieved. When normalized using Method 2 (not shown), profiles are similar to those shown for Method 1 but shifted slightly to the left, given the slightly higher val- ues of $u_{*}$. There is also less separation between the RC1 and $\mathrm{RC} 2$ groups. Inflow profiles determined using Method 3 produce a better match to the full-scale data for mean speed for the $\mathrm{RC} 1$ group although they remain higher for TKE. For the RC2 group, profiles remain slightly higher than full scale for mean speed and are shifted even further to the right for TKE, due to the higher values of $u_{*}$. Profiles normalized using Method 4 are similar to those of Method 1, with profiles collapsing to a greater extent within the $\mathrm{RC} 1$ and $\mathrm{RC} 2$ groups.

Upwind Reynolds shear stress $-\overline{u^{\prime} w^{\prime}}$ as a function of height is shown in Fig. 5 for the WindEEE cases. Magnitudes of shear stress (Fig. 5a) are shown to increase with Reynolds number, and the higher roughness (RC1) cases exhibit consistently higher shear stress than the lower roughness (RC2) cases. When normalized by $u_{* 05}^{2}$, where $u_{*}$ is calculated using Method 1 (Fig. 5b), the shear stress profiles generally tend to collapse, with some deviations, notably the lower values of the U5 cases at higher elevations and the higher value of the U15RC1 case near hill height $(Z=11.73 \mathrm{~m})$. The value of the non-dimensional Reynolds shear stress for $\mathrm{U} 15 \mathrm{RC} 1$ is about $60 \%$ higher than that of the U14RC1 case in this high shear region.

Inflow integral length scales in the streamwise direction $L_{\mathrm{uu}}$ are shown in Fig. 5c. Timescales were determined by computing the integral of the autocorrelation function, up to the first zero crossing of the $x$ axis, and invoking Taylor's hypothesis, i.e. multiplying by mean velocity $U$, to yield the length scales. There is a noticeable trend among the uniform profiles of increasing length scale with Reynolds number; however, the U15RC1 shear case has the lowest length scales among all RC1 cases despite having the highest Reynolds 

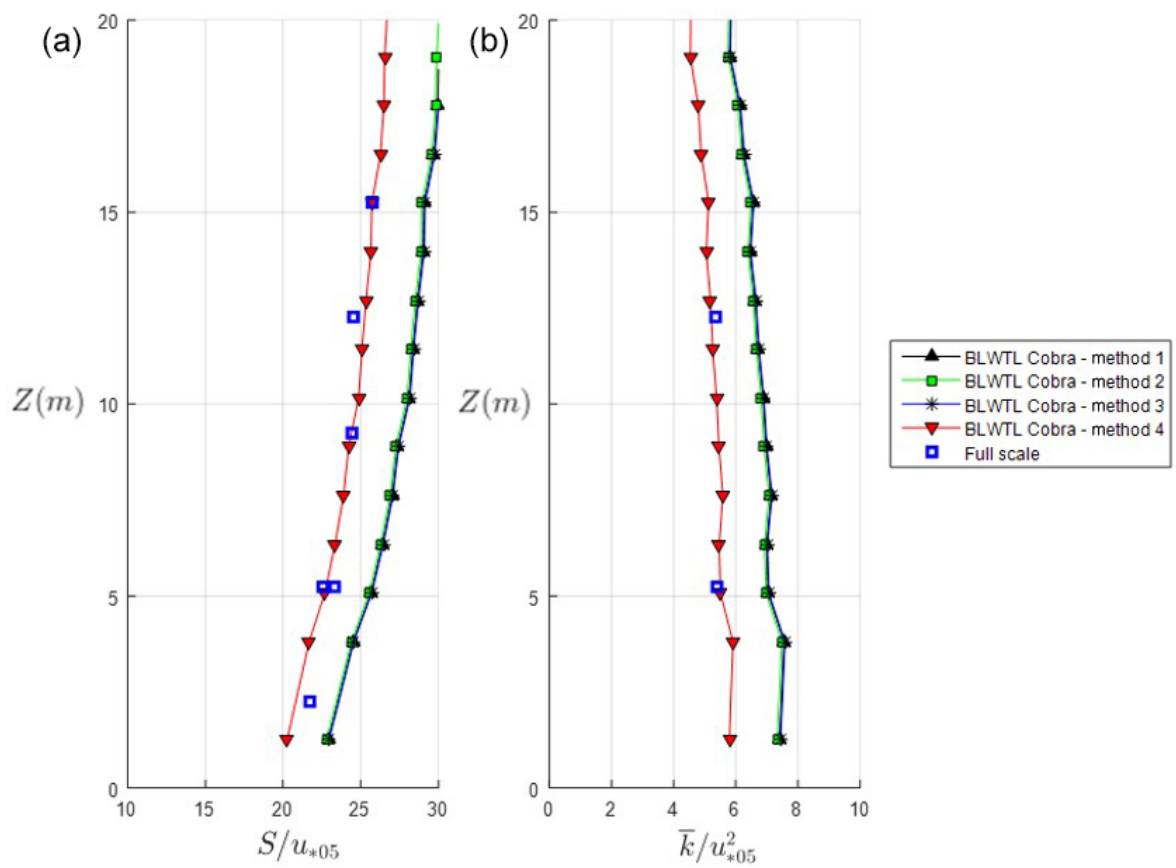

Figure 6. BLWTL inflow profiles of (a) mean flow speed and (b) TKE, normalized by friction velocity obtained using four different methods.

number. The difference is particularly large at hill height. Based on the results presented in Figs. 4 and 5, it can be inferred that the inflow profile for the shear case is characterized by eddies with smaller average size and higher levels of momentum transport than for the uniform fan cases, particularly near hill height.

\subsection{BLWTL inflow profiles}

The key inflow parameters for the BLWTL Cobra probe measurements are shown in Table 1 . Friction velocity was calculated according to each of the four methods outlined above, and $z_{0}$ was estimated using Method 3. Friction Reynolds number $u_{*} z_{0} v^{-1}$ was 1.39 ; thus, the inflow was in the transitionally rough regime (Bowen, 2003). Figure 6 shows inflow profiles from the BLWTL Cobra probe data, measured at the inflow reference location of $X=-1.82 \mathrm{~m}$ in model scale ( $X=-182 \mathrm{~m}$ in full scale). Mean speed and TKE were normalized by friction velocity calculated using the four methods identified above. The results show that the profiles for Methods 1-3 are quite close to each other and higher than the full-scale data points, while Method 4, with higher $u_{*}$, produced profiles shifted slightly to the left and matched particularly well with the full-scale data. The reduction in normalized TKE with height was consistent with the inflow profiles measured by Yeow et al. (2015) but different from the WindEEE and full-scale TKE profiles, which were relatively constant with height over the measurement region. Similarities between the inflow profile of the BLWTL experiment and those of Yeow et al. (2015) were expected given that $u_{*}$ and $z_{0}$ are almost of the same order for both studies, making $u_{*} z_{0} v^{-1}$ similar. Inflow turbulence intensity was roughly 0.1 , and $\delta / h$ was 10.6 for the BLWTL case (see Table 1 ).

\section{Results and discussion}

The results are divided into two main sections: analysis of the mean flow behaviour, and analysis of the turbulent flow behaviour. Most of the results presented were obtained from the WindEEE PIV data, while some additional data are presented from the WindEEE and BLWTL Cobra probe measurements.

\subsection{Mean flow behaviour}

The streamlines of the mean flow field are shown in Fig. 7 for $\mathrm{U} 5, \mathrm{U} 8, \mathrm{U} 14$, and $\mathrm{U} 15$ cases at the higher roughness configuration (RC1). Mean streamlines for the RC2 cases (not shown) were nearly identical to those shown for RC1. The streamlines depict a region of flow acceleration over the escarpment leading edge and deceleration moving downwind. Streamlines for the three uniform cases collapse tightly, while the U15RC1 shear case shows higher speeds over the hill. None of the streamlines for the mean flow showed clear evidence of recirculation. Even upon close inspection of the mean flow field in the vicinity of the escarpment, it is difficult to ascertain whether the negative values of streamwise velocity observed in the separated flow region are indicative of recirculation or due to other factors such as near-wall effects. Furthermore, the higher uncertainty in this region, due to very high velocity gradients, prohibits drawing a firm con- 


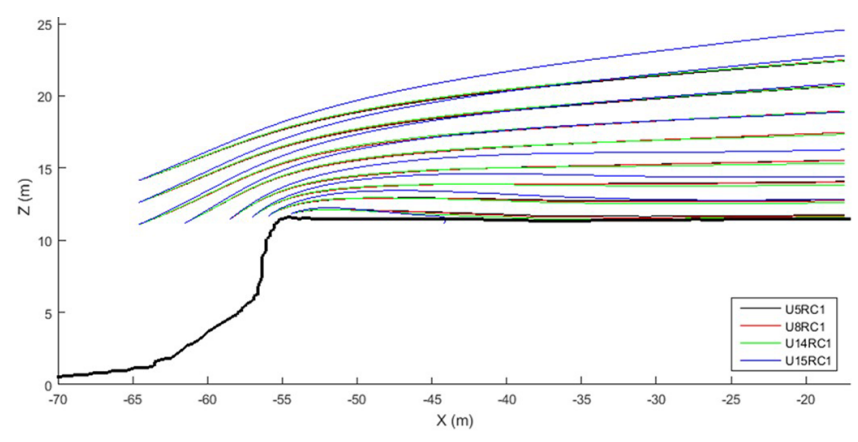

Figure 7. Streamlines of mean velocity for various cases with roughness configuration $\mathrm{RC} 1$.
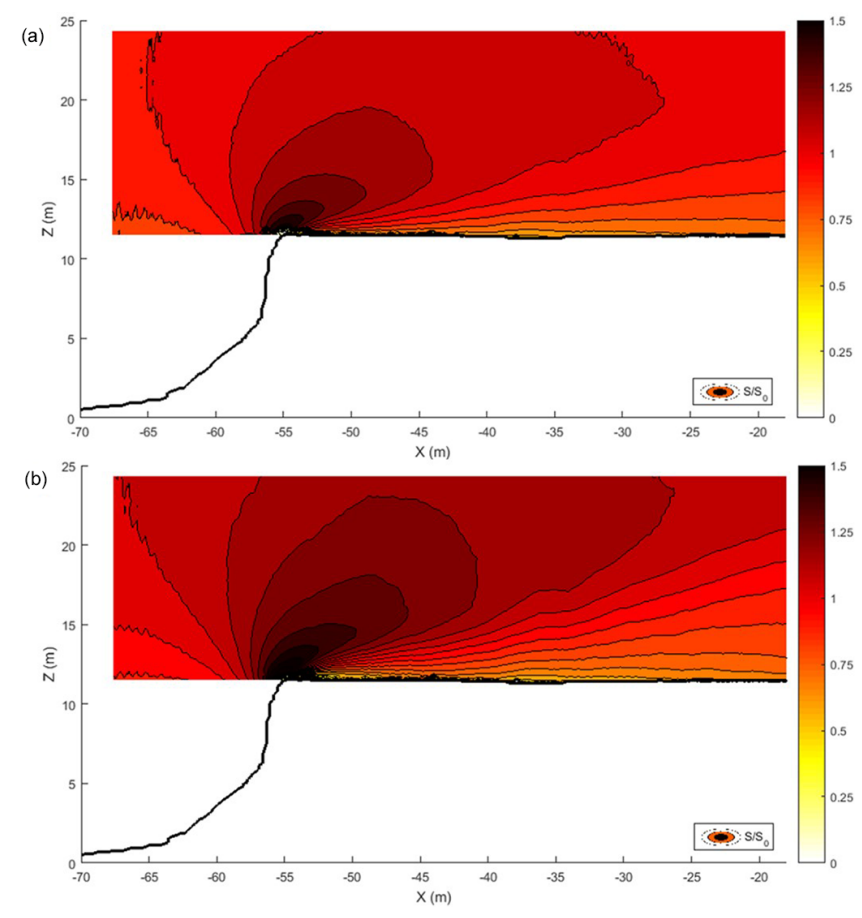

Figure 8. Contours of speed-up ratio $\left(S / S_{0}\right)$ for (a) U14RC1 and (b) U15RC1.

clusion about the presence of a recirculation zone. An analysis of the probability of occurrence of negative instantaneous velocity vectors in the streamwise direction for each case was conducted in a manner analogous to Yeow et al. (2015). For all cases, it was observed that, apart from a very small near-surface region close to the escarpment leading edge, the probability of occurrence of negative vectors was less than $1 \%$, which further decreased with an increase in downwind distance and height. This is consistent with the results presented by Yeow et al. (2015). The U15RC1 shear case had a relatively higher occurrence of negative vectors over a wider region above the hill surface compared to the uniform cases U14RC1 and U14RC2, which were similar to each other.
Contour plots of speed-up ratio for U14RC1 (Fig. 8a) and U15RC1 (Fig. 8b) clearly illustrate the speed-up region near the escarpment and the re-establishment of the boundary layer on top of the hill. The U5 and U8 contour plots (not shown) were very similar to the U14 case, analogous to the similarity observed in the streamline plots between the three cases. While speed-up is generally similar between the U14RC1 and U15RC1 cases, slightly higher values are observed for U15RC1 in the vicinity of the escarpment, and this case also shows a more elongated, oblong shape of the speedup region at the escarpment edge. The Reynolds number for the two flows did not differ by a great amount $\left(4.57 \times 10^{5}\right.$ for U14RC1 vs. $5.21 \times 10^{5}$ for U15RC1), i.e. much less than the difference in Reynolds number between the U5RC1 and U14RC1 cases, indicating that the difference in normalized mean flow behaviour can be most likely attributed to the higher inflow shear for the U15 case.

\subsection{Mean flow comparison to previous experiments}

In addition to the full-scale measurements, results from previous physical modelling of the Bolund Hill are available in the literature for comparison to the present results. These include wind tunnel and water channel experiments from the blind comparison (Bechmann et al., 2011), wind tunnel PIV and three-component hot-wire (3CHW) tests conducted by Yeow et al. (2015) on a $1: 115$ scale at two Reynolds numbers $\left(4.15 \times 10^{4}\right.$ and $\left.8.21 \times 10^{4}\right)$, and wind tunnel PIV modelling conducted by Conan et al. (2016) on a $1: 500$ scale and $R e=2.1 \times 10^{4}$. Benchmarking the WindEEE Cobra probe and PIV and the BLWTL Cobra probe results from the present experiment against these data sets provides some validation of the present experimental procedure and also serves as an initial point of discussion on the differences between conducting the same experiment on three scales, i.e. wind tunnel $\left(R e \sim 10^{4}\right)$, WindEEE $\left(\operatorname{Re} \sim 10^{5}\right)$, and full scale $\left(4.25 \times 10^{6}<\operatorname{Re}<1.02 \times 10^{7}\right)$.

Figure 9 shows horizontal profiles of the wind speed-up at two locations corresponding to the full-scale mast measurement positions at heights of $z=2 \mathrm{~m}$ (Fig. 9a) and $z=5 \mathrm{~m}$ (Fig. 9b) above hill surface level. Results from the WindEEE PIV data and those of previous experiments mentioned above are presented for comparison. The topography and the mast locations are shown in Fig. 9c for reference. Figure 10 shows the comparison for vertical profiles at three locations along the hill. The U14RC1 and U15RC1 cases were selected from the eight WindEEE PIV cases as representative cases to avoid clutter; the differences between the WindEEE cases are discussed further below. From the horizontal profiles, agreement is generally quite good between all data sets at $z=5 \mathrm{~m}$, whereas significant variability is observed at $z=2 \mathrm{~m}$, which is within the highly turbulent shear layer observed in the TKE contour plots (see Fig. 14), also referred to by Yeow et al. (2015) and observed in the scanning lidar data (Lange et al., 2016a). Similarly for the vertical profiles, better agree- 

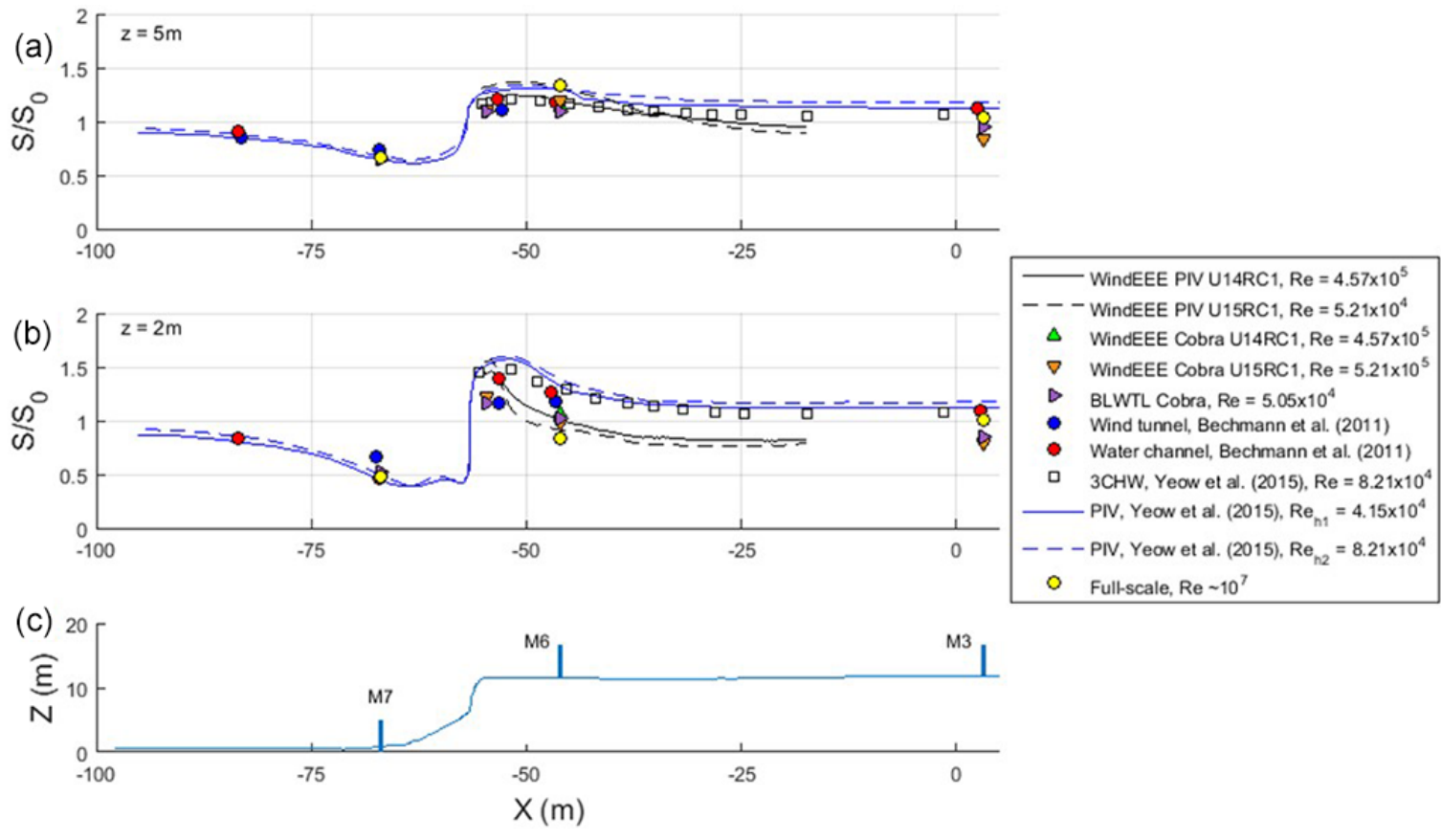

Figure 9. Horizontal profiles of speed-up ratio from PIV and Cobra probe measurements (WindEEE and BLWTL cases) at (a) $z=5 \mathrm{~m}$ and (b) $z=2 \mathrm{~m}$ above hill surface, with (c) showing hill profile. Results from full scale and other previous physical experiments presented for comparison.
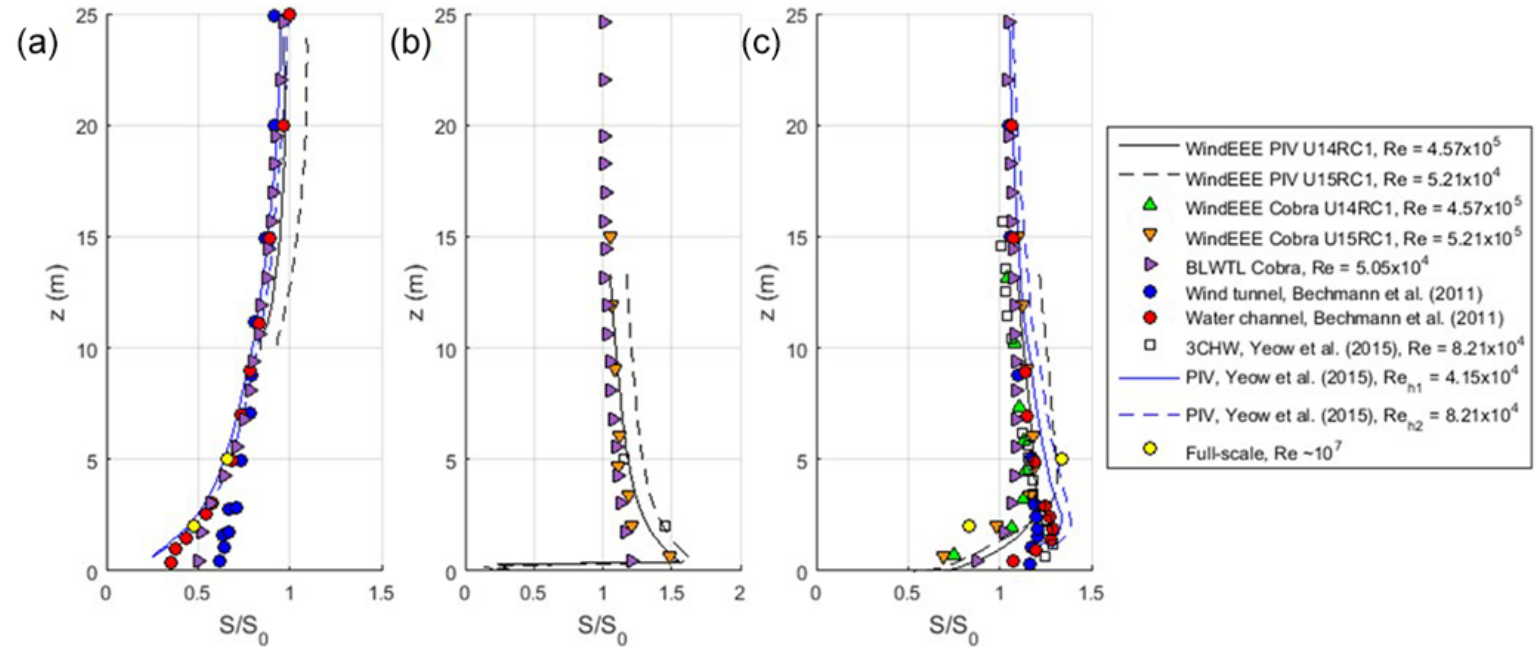

Figure 10. Vertical profiles of speed-up ratio for WindEEE and BLWTL cases at (a) M7 $(X=-66.9 \mathrm{~m}),(\mathbf{b})$ escarpment $(X=-54.7 \mathrm{~m})$, and (c) M6 $(X=-46.1 \mathrm{~m})$. Results from full scale and other previous physical experiments presented for comparison.

ment is observed at position M7 upwind of the escarpment (Fig. 10a), with greater variability seen at the other two positions (Fig. 10b, c), particularly at $z<5 \mathrm{~m}$.

\subsection{Influence of inflow parameters on the mean flow}

The WindEEE experiments were conducted by changing one variable at a time, allowing for the influence of a particular modifier to the flow to be isolated and the resultant flow be- haviour to be analysed. In this section, the isolated effects of Reynolds number, inflow roughness, shape of the inflow profile, and model and measurement resolution on the mean flow behaviour are discussed. 

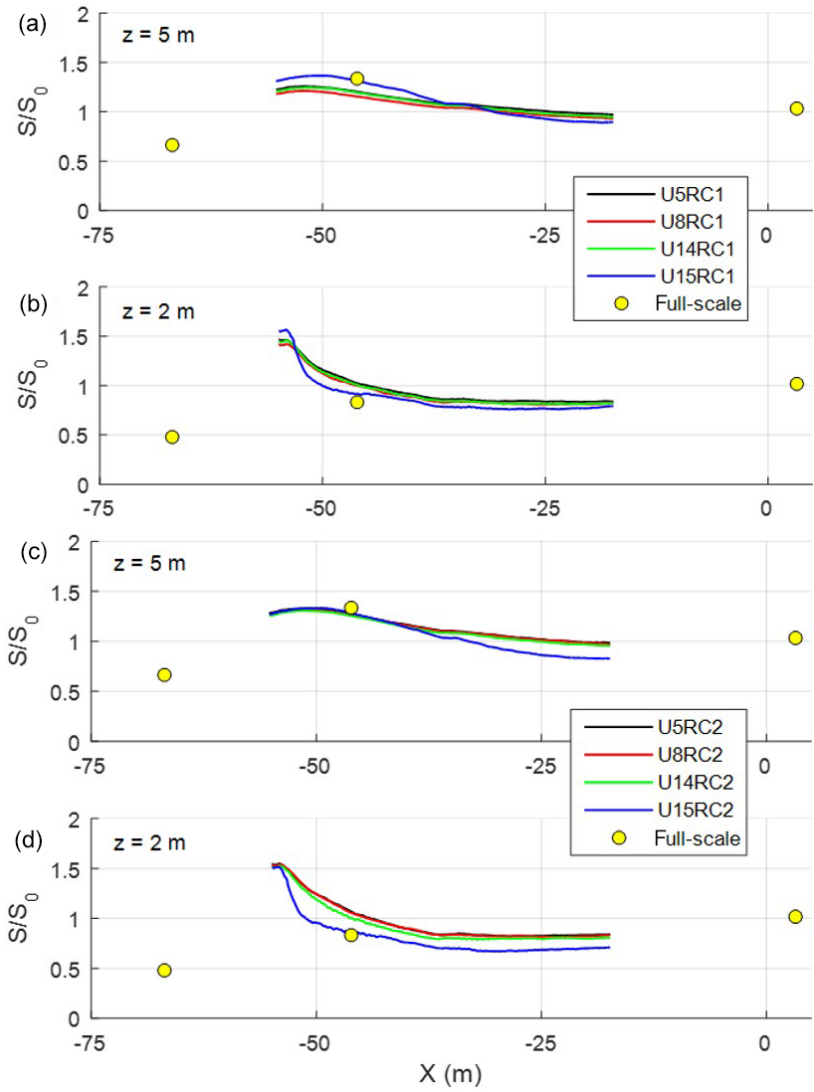

Figure 11. Horizontal profiles of speed-up ratio for (a) $\mathrm{RC} 1$ cases, $z=5 \mathrm{~m}$, (b) RC1 cases, $z=2 \mathrm{~m}$, (c) RC2 cases, $z=5 \mathrm{~m}$, and (d) RC2 cases, $z=2 \mathrm{~m}$.

\subsubsection{Effect of Reynolds number and inflow wind profile on the mean flow}

The horizontal profiles of the wind speed-up for four Reynolds numbers at full-scale heights of $z=5 \mathrm{~m}$ and $z=$ $2 \mathrm{~m}$ above the island surface level are shown for two inflow roughness cases: higher roughness RC1 in Fig. 11a and lower roughness RC2 in Fig. 11b. Full-scale data are also plotted for reference. The normalized mean flow results show almost identical trends for the three uniform fan speed cases (U5, U8, and U14) for both RC1 and RC2. This indicates an absence of Reynolds number effects on the mean flow over a Reynolds number range of $1.7 \times 10^{5}$ to $4.6 \times 10^{5}$. The U15 case, however, with a modified inflow shear profile, displays different behaviour than the uniform fan speed cases. The U15RC1 peak speed-up is higher at the escarpment compared to the other RC1 cases (by about $9 \%$ at $z=5 \mathrm{~m}$ and by $7 \%$ at $z=2 \mathrm{~m}$ ) and then changes to become relatively lower further downwind. For the U15RC2 case, speed-up is generally equal to or slightly lower than the other RC2 cases at $z=5 \mathrm{~m}$ (Fig. 11c) and lower along horizontal locations at $z=2 \mathrm{~m}$ (Fig. 11d). In Fig. 12, a similar comparison is made along the vertical profiles at M6. Results show a trend simi-
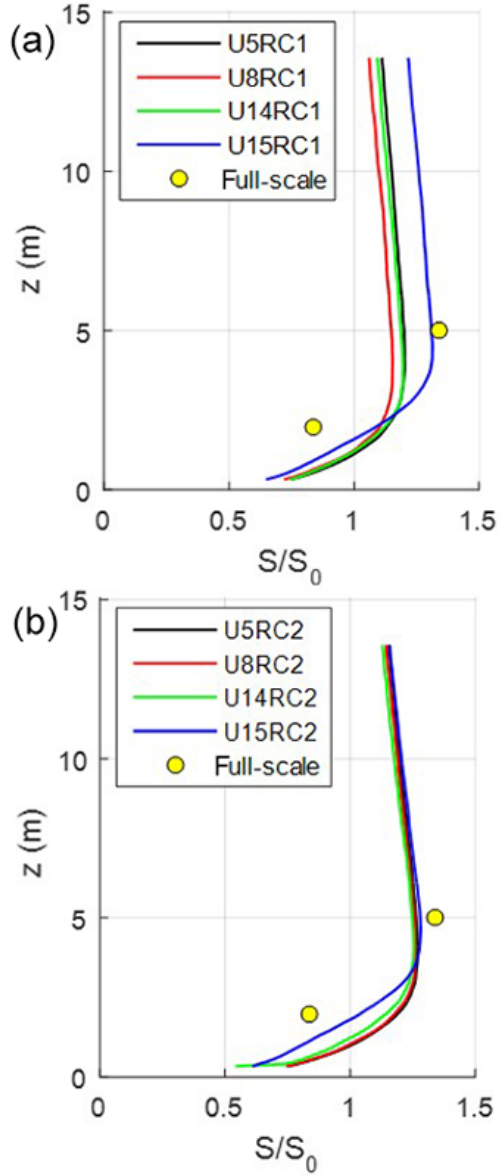

Figure 12. Vertical profiles of speed-up ratio at M6 for (a) RC1 cases and (b) RC2 cases.

lar to that observed for the horizontal profiles, i.e. little difference among the mean flow profiles in three uniform fan speed cases, with the RC2 profiles collapsing more closely. Again the U15RC1 case (Fig. 12a) shows different behaviour, with a higher speed-up than the other cases (i.e. about $9 \%$ higher than U5RC1 at $z=5 \mathrm{~m}$ ) and also shows a better match to the full-scale data points. For RC2 (Fig. 12b), the U15 case generally collapses with the others, with the only difference being the relatively lower speed-up at $z<4 \mathrm{~m}$ (i.e. $12 \%$ lower than U5RC1 at $z=2 \mathrm{~m}$ ), which is again closer to the fullscale behaviour.

\subsubsection{Effect of inflow roughness on the mean flow}

The comparison of speed-up profiles at the same Reynolds number but a different roughness configuration provides an insight into the effect of inflow surface roughness, $z_{0}$, on the mean flow behaviour over the escarpment. Such analysis can be obtained by comparing the vertical profiles in Figs. 11 and 12 for two roughness cases. Generally, the speed-up profiles for the same Reynolds number under the two different inflow roughness configurations were similar, despite the 
$\mathrm{RC} 1 z_{0}$ value being higher than the RC2 value by about 3 orders of magnitude. For the uniform fan speed cases, the peak speed-up at $z=2 \mathrm{~m}$ was higher for the RC2 cases than RC1 by margins of about 6,8 , and $5 \%$ for U5, U8, and U14, respectively. In the horizontal profiles, a lower inflow $z_{0}$ was found to generate a roughly $5 \%$ higher peak speed-up at the escarpment, with a diminishing effect moving downwind. A different trend was observed for the U15 cases, where a slight reduction in peak speed-up of about $3 \%$ was observed at the escarpment for the $\mathrm{RC} 2$ case, with the difference between the two roughness cases growing slightly moving downwind. At M6, the lower roughness cases showed a slightly better match to the full-scale data (see Fig. 12).

\subsubsection{Effect of measurement and model resolution on the mean flow}

The Cobra probe measurements were taken under identical fan speed and roughness element configurations to the PIV cases, although not simultaneously, and therefore from the mean flow perspective, they provide useful independent evidence for Reynolds number dependence. A comparison of speed-up ratio between PIV and Cobra probe measurements, for the three uniform fan speed cases, for both roughness configurations, along the same vertical profile at M6, is shown in Fig. 13. The results show very good matching between the two methods of measurements, with some systematic bias error resulting in slightly lower speed-up for Cobra probe measurements, perhaps due to PIV calibration. Notwithstanding, very little evidence of Reynolds number dependence is observed between the Cobra probe profiles, confirming the trends observed earlier in the PIV data.

Now turning to the discussion on the effect of model resolution on the mean flow, it is generally accepted by wind tunnel modellers that for bluff bodies submerged in deep boundary layers, Reynolds number effects are negligible for $\operatorname{Re}>(2-3) \times 10^{4}$, particularly for flows without steady vortical regions (Lim et al., 2007). The BLWTL case and the WindEEE cases under uniform fan speed, as well as the two tests conducted by Yeow et al. (2015), at $R e=4.15 \times 10^{4}$ and $R e=8.21 \times 10^{4}$, were all above this threshold. The WindEEE uniform fan speed cases are consistent with the literature in showing a lack of Reynolds number dependence. One would therefore expect to see Reynolds number independence preserved between normalized speed-up profiles at the BLWTL scale $(1: 100)$ and the WindEEE scale $(1: 25)$, measured using the same instrument, under similar inflow conditions. Such a comparison is made in Fig. 10, which shows speed-up profiles from Cobra probe measurements for the BLWTL and WindEEE cases. Some discrepancies are observed, particularly at M6 at $z<5 \mathrm{~m}$, where the WindEEE U14RC1 measurements were found to be higher than the BLWTL values by about $5 \%$ and a better match to the full-scale measurements. It can therefore be concluded that the discrepancies between Cobra probe results observed at the two different
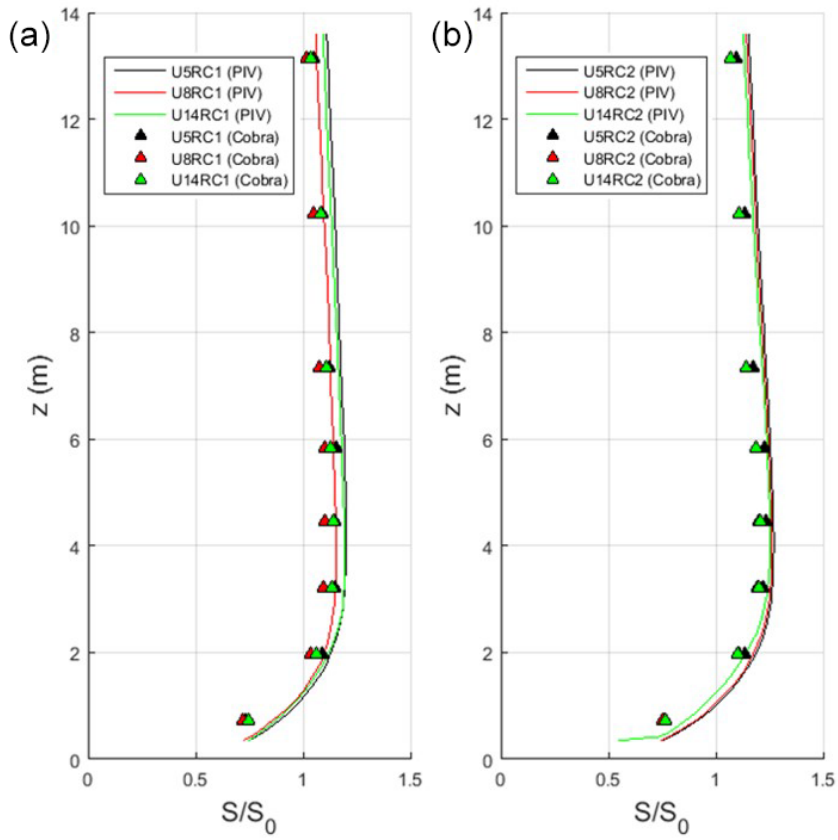

Figure 13. Vertical profiles of speed-up ratio from WindEEE PIV and Cobra probe at M6 for (a) RC1 and (b) RC2.

model resolutions are unlikely to be due to Reynolds number effects but rather caused by other factors such as proximity of the measurement instrument to the surface, size of the instrument relative to the model and surface roughness of the model.

\subsection{Turbulent flow behaviour}

The results for the turbulent flow are presented in a similar manner as for the mean flow behaviour in Sect. 5.1. To obtain a better insight into the overall turbulent flow behaviour, contour plots of the change in TKE $\Delta \bar{k}$ over the same area as in the earlier speed-up plots are shown in Fig. 14a and b for U14RC1 and U15RC1, respectively. A highly turbulent region is observed at the escarpment, which dissipates moving downwind. Several significant differences are observed between the two cases, with U15RC1 having a larger highintensity TKE region near the escarpment and a longer and higher wake. The TKE increment also begins further upwind of the escarpment. The U5 and U8 TKE contour plots (not shown) were similar to the U14 case but with slightly lower values of $\Delta \bar{k}$ throughout.

\subsection{Turbulent flow comparison with previous experiments}

A comparison of horizontal profiles of WindEEE TKE increment against previous experimental results at $z=5 \mathrm{~m}$ and $z=2 \mathrm{~m}$ above surface level is presented in Fig. 15. The two WindEEE PIV profiles stand out from the others as they fea- 

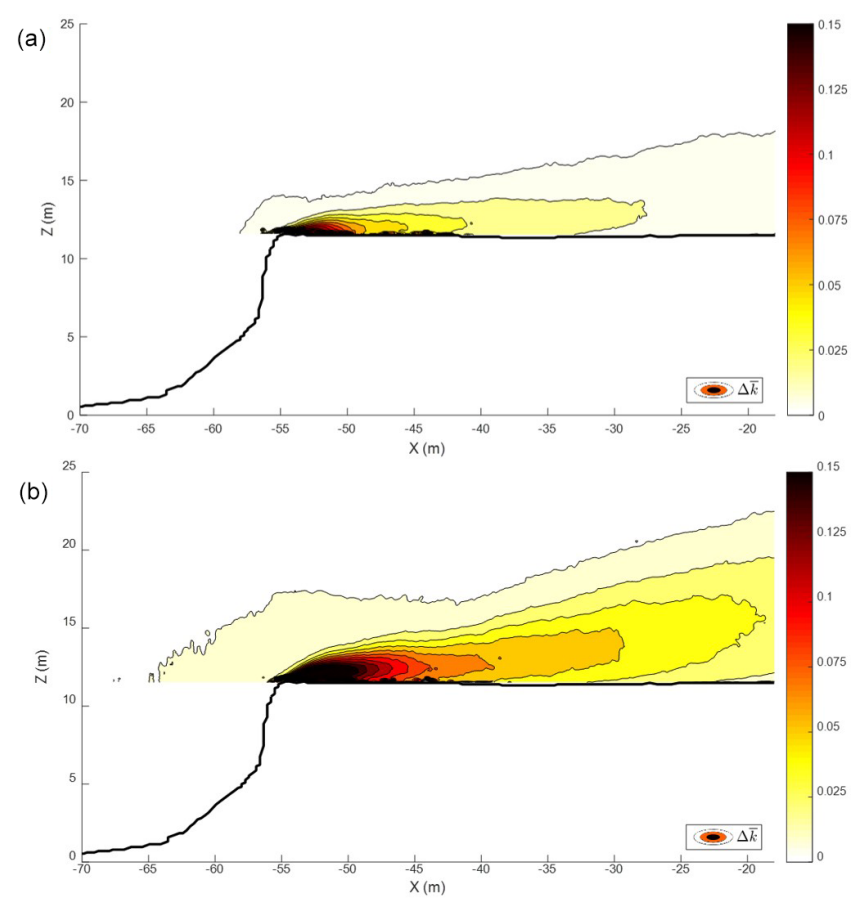

Figure 14. Contours of mean TKE increment $\Delta \bar{k}$ for (a) U14RC1 and (b) U15RC1.

ture a shallow hump between M6 and M3 at $z=5 \mathrm{~m}$ and a sharp spike between the escarpment and M6 at $z=2 \mathrm{~m}$. Both features are much more pronounced for the U15RC1 case compared to U14RC1. The Cobra probes were not able to capture the TKE spike to the same extent, also observed in the vertical profile at M6 (see Fig. 16). As was the case for the speed-up ratio, the U15RC1 case was observed to better approximate the full-scale values of $\Delta \bar{k}$ than the others.

\subsection{Influence of inflow parameters on the turbulent flow}

Similar to the mean flow analysis, the effects of inflow Reynolds number, wind shear profile, upwind roughness, and model and measurement resolution on the turbulent flow behaviour are discussed in the following sections.

\subsubsection{Effect of Reynolds number and inflow wind profile on the turbulent flow}

Figure 17 shows horizontal profiles of $\Delta \bar{k}$ for the four wind speed cases at RC1 and RC2, respectively. The two U15 profiles stand out from the other cases - the peak TKE increment for U15RC1 was about $200 \%$ higher than that for U14RC1 - and the discrepancy is much more significant than it was for the speed-up ratio. The TKE results indicate that changes in the flow behaviour above the escarpment can be attributed to changes in the inflow parameters and elicit the following question: which are the relevant non-dimensional parameters? As noted previously, the only difference between the
U14 and U15 cases was the $50 \%$ increase in the operating speed of fans in the third row from the floor compared to all other fans. This induced a strong shearing effect at the interface between fan rows 2 and 3 , about $2 \mathrm{~m}$ above the floor in model scale or $50 \mathrm{~m}$ in full scale, just over 4 times the hill height. The higher fan speed in the third row produced a slightly higher Reynolds number at hill height for the U15 cases than for the U14 cases, but the Reynolds number difference was small compared to the difference between the uniform cases and thus unlikely to be a significant contributor to the TKE difference. Similarly, the non-dimensional TKE profiles (see Fig. 4) show little difference between the $\mathrm{U} 15 \mathrm{RC} 1$ case and the three other RC1 cases. As discussed, more significant differences between the shear and uniform cases were observed among the inflow profiles of Reynolds shear stress and integral length scale (see Fig. 5), parameters which are known to influence turbulence behaviour and momentum transport. As shown by the inflow profiles, by the time the flow reaches the upwind reference position, the shearing effect introduced at the fan wall for the U15 shear case appears to produce turbulence characterized by smaller eddies with higher momentum compared to the uniform cases at the hill height. The results highlight the important fact that a relatively small change to the inflow wind shear profile, even well above the height of the topography, can significantly affect the turbulent flow behaviour near the surface.

Among the three uniform fan speed horizontal profiles, there is little difference in TKE increment at $z=5 \mathrm{~m}$; however, at $z=2 \mathrm{~m}$, peak TKE increment for the U14RC1 case is about $17 \%$ higher than U5RC1 and $29 \%$ higher than U8RC1 in the other two cases. A similar trend is observed for the RC2 cases, where peak TKE increment for U14RC2 is about $25 \%$ higher than U5RC2 and $27 \%$ higher than U8RC2, indicating a possible Reynolds number dependence in this region. Vertical profiles of TKE increment at M6 were also plotted (see Fig. 18) for the RC1 and RC2 cases. The profiles for the uniform fan speed cases again tended to collapse, with the exception of the U14 cases below $z=2 \mathrm{~m}$. Peak TKE increment at M6 for U14RC1 was about $7 \%$ higher than U5RC1, and $13 \%$ higher than U8RC1 and the peak value for U14RC2 was about higher $10 \%$ higher than U5RC2 and $14 \%$ higher than U8RC2.

\subsubsection{Effect of inflow roughness on the turbulent flow}

The influence of inflow roughness can be seen in Fig. 18. For the uniform fan speed cases, configuration RC2, with lower $z_{0}$, appeared to cause a moderate increase in peak TKE increment of about $40 \%$ at M6 compared to RC1, while little difference in TKE was observed between the two U15 cases. A comparison of horizontal profiles of RC1 and RC2 cases (not shown) showed a higher TKE increment for the RC2 cases at all positions downwind of about $X=-50 \mathrm{~m}$, particularly for the $z=2 \mathrm{~m}$ profile. The difference in peak TKE increment 

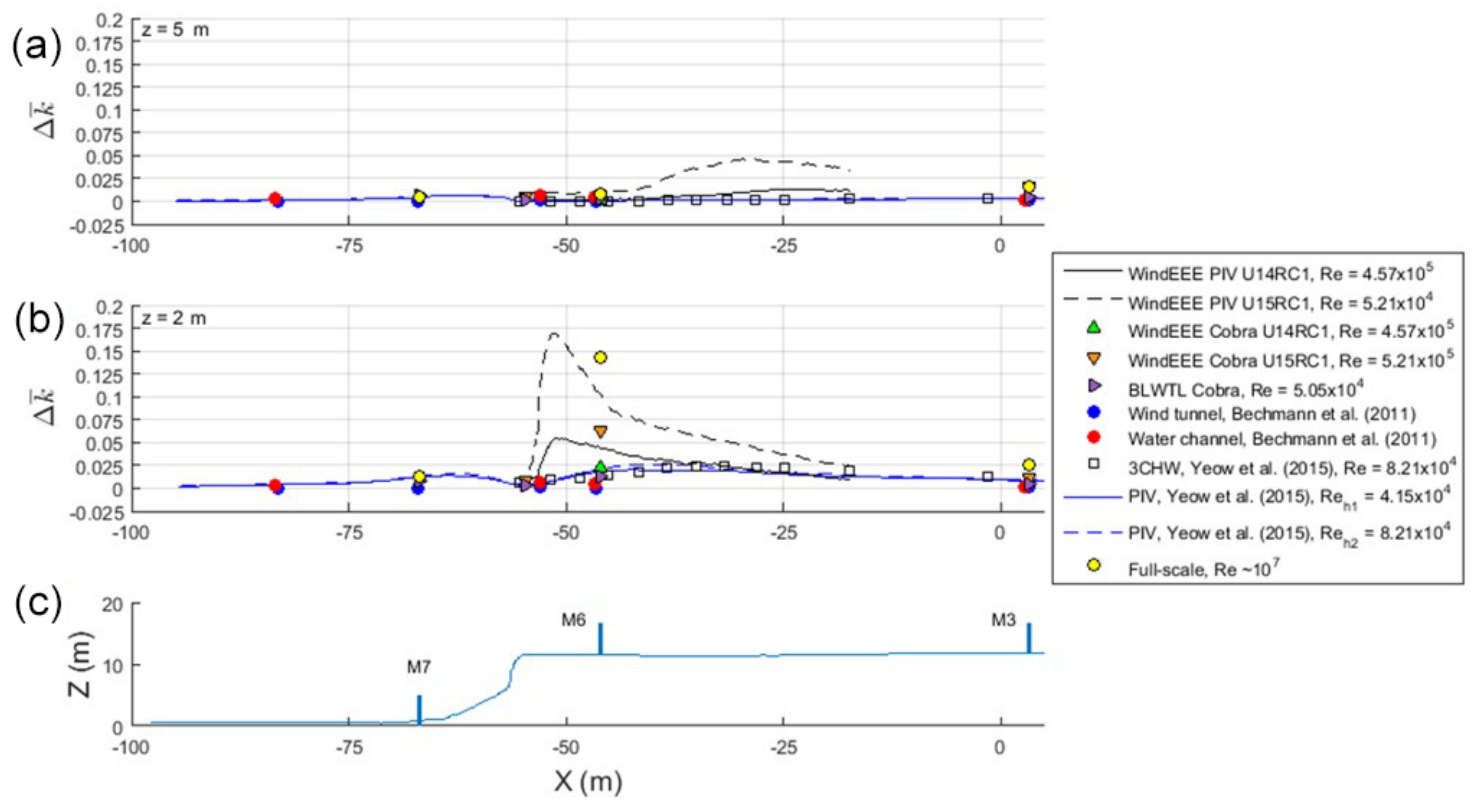

Figure 15. Horizontal profiles of TKE increment $\Delta \bar{k}$ from PIV and Cobra probe measurements (WindEEE and BLWTL cases) at (a) $z=5 \mathrm{~m}$ and (b) $z=2 \mathrm{~m}$ above hill surface, with (c) showing hill profile. Results from full scale and other previous physical experiments shown for comparison.
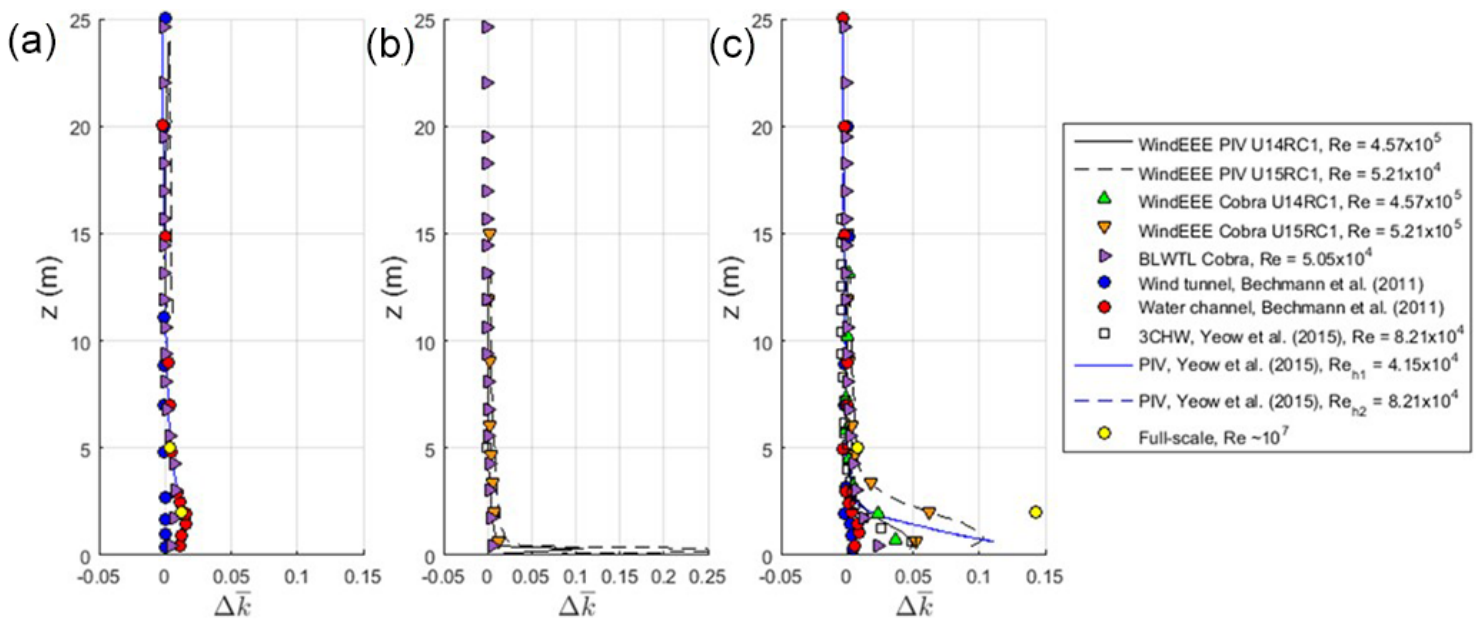

Figure 16. Vertical profiles of TKE increment $\Delta \bar{k}$ from PIV and Cobra probe measurements (WindEEE and BLWTL cases) at (a) M7 $(X=-66.9 \mathrm{~m})$, (b) escarpment $(X=-54.7 \mathrm{~m})$, and (c) M6 $(X=-46.1 \mathrm{~m})$. Results from full scale and other previous physical experiments shown for comparison.

at different roughness configurations was about 13,28 , and $27 \%$ for $\mathrm{U} 5, \mathrm{U} 8$, and $\mathrm{U} 14$, respectively, with the $\mathrm{RC} 2$ value being higher in each case. A negligible difference in TKE increment was generally observed between the two U15 cases at most locations. Peak TKE increment at $z=5 \mathrm{~m}$ was about $7 \%$ higher for U15RC1 than U15RC2. Thus, a change in the inflow roughness was observed to have a moderate effect on the TKE increment for the uniform fan speed cases, while the shear case appeared to be more resilient to changes in the inflow roughness.

\subsubsection{Effect of model and measurement resolution on the turbulent flow}

A comparison of TKE increment between WindEEE PIV and WindEEE Cobra probe measurements for the same Reynolds number and for the same vertical profile at M6 is presented in Fig. 19. A strong similarity is observed between the two types of measurements, from the top of the measurement window down to about $z=3 \mathrm{~m}$, at which point some divergence is observed, with the Cobra probes being unable to 

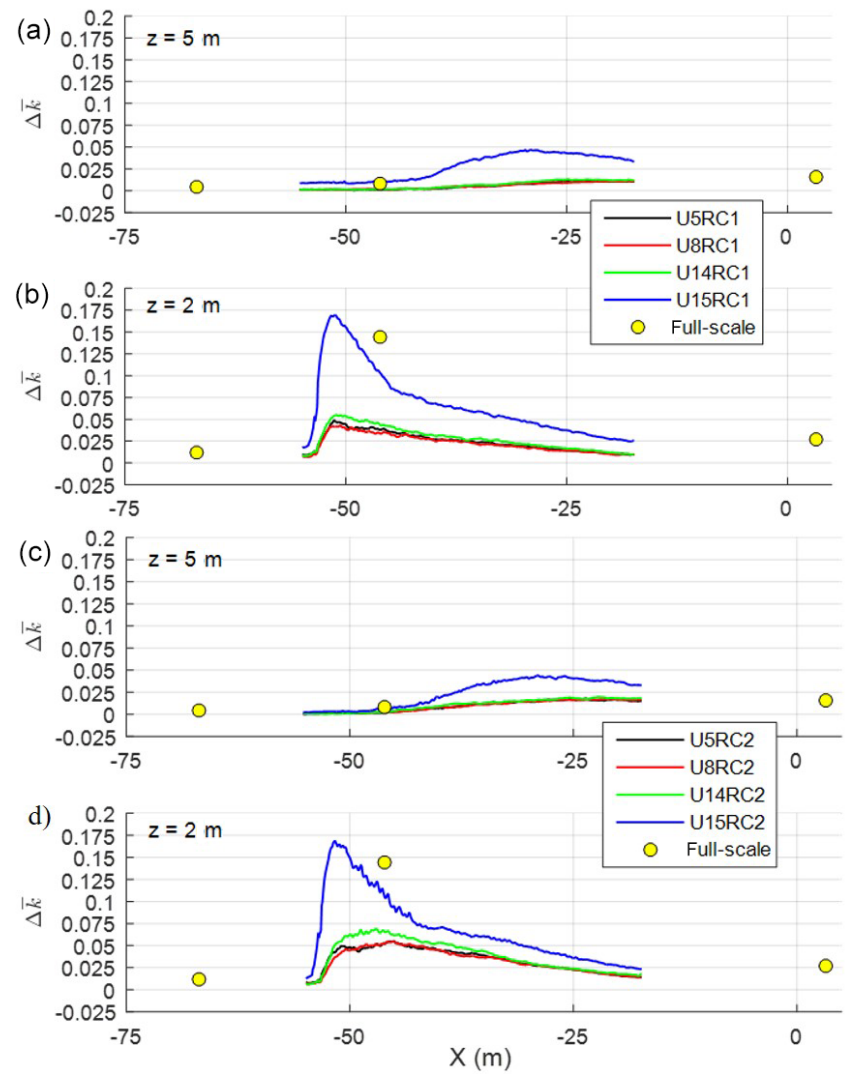

Figure 17. Horizontal profiles of TKE increment $\Delta \bar{k}$ for (a) RC1 cases at $z=5 \mathrm{~m}$, (b) $\mathrm{RC} 1$ cases at $z=2 \mathrm{~m}$, (c) $\mathrm{RC} 2$ cases at $z=$ $5 \mathrm{~m}$, and (d) RC2 cases at $z=2 \mathrm{~m}$.

capture the spike in TKE to the same extent as the PIV measurements, which may be partially due to the reverse flow at this location. Although Reynolds number effects may contribute to the higher TKE for the U14 PIV profile at $z<3 \mathrm{~m}$, Reynolds number independence appears to be almost completely preserved among the three Cobra probe profiles all the way down to the hill surface. This observation once again raises the question of why the measurements using the $1: 25$ scale model at WindEEE are higher than those using the $1: 100$ BLWTL model and why they more closely approximate the full-scale measurements, as seen in Fig. 16c at M6. The resolution of the model and the ability to measure closer to the surface level thus appears to be one contributing factor. A separate study by Lange et al. (2016b) recently submitted for publication investigates the effect of sharpening the escarpment edge. Preliminary analysis shows that this has a significant effect on the flow behaviour in the near-surface region.

\section{Conclusions}

An experimental investigation to characterize the mean and turbulent flow behaviour over a steep escarpment, repre-
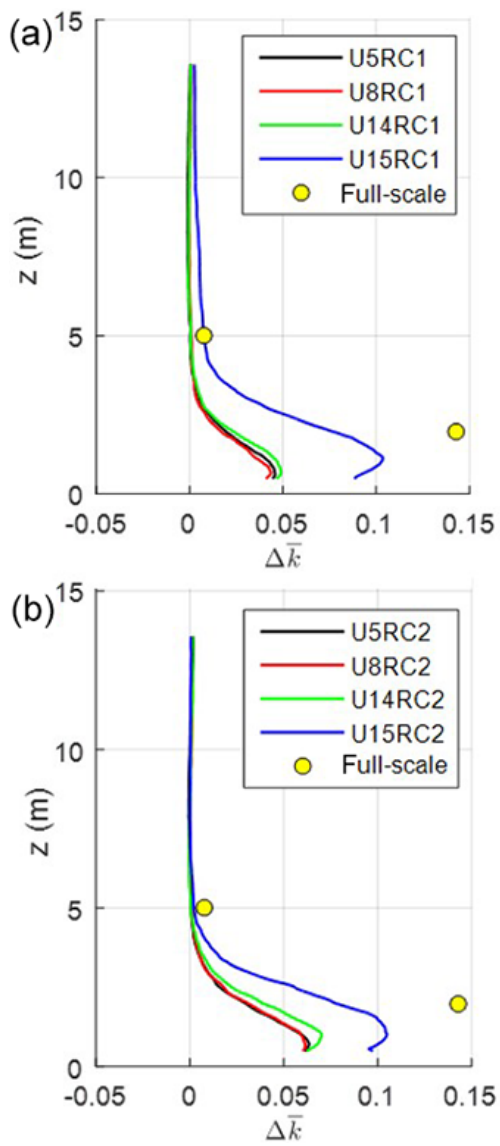

Figure 18. Vertical profiles of TKE increment $\Delta \bar{k}$ at M6 for (a) RC1 cases and (b) RC2 cases.

sented by the topography of Bolund Hill, was conducted on two distinct scales $(1: 100$ and $1: 25)$ by means of wind tunnel testing using PIV and Cobra probes. A range of Reynolds numbers, boundary layer inflow profiles, and inflow roughness values were examined. At WindEEE, three uniform fan profiles and one modified shear profile were tested at two different inflow roughness configurations, for a total of eight unique sets of inflow conditions. These results, presented in the form of normalized speed-up and TKE increment, were compared to each other and to measurements from the field campaign and previous experimental work to attempt to establish the relative contributions of the key inflow parameters to flow behaviour over the hill.

Mean flow behaviour was found to be generally resilient to changes in inflow conditions, with negligible a Reynolds number dependence observed between the uniform fan speed cases, across a Reynolds number range of $1.7 \times 10^{5}$ to $4.6 \times$ $10^{5}$ for both Cobra probe and PIV measurements. A slight modification of the speed-up behaviour was observed for the shear profile case, but this did not appear to be related to the Reynolds number. Lower inflow roughness was observed to cause a marginal increase in peak speed-up at the escarp- 

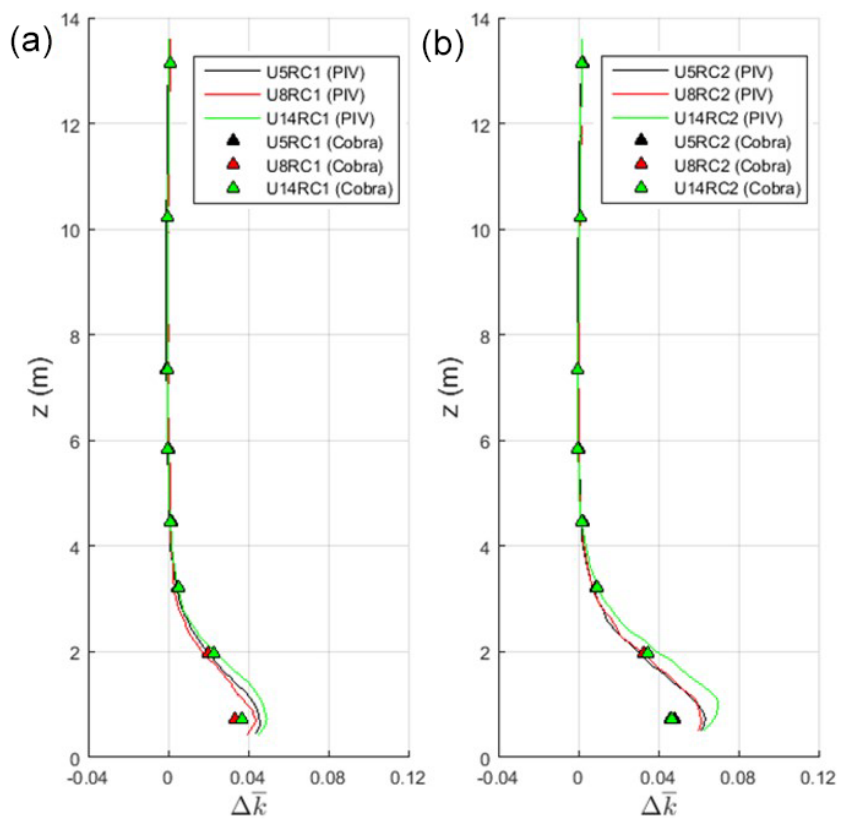

Figure 19. Vertical profiles of TKE increment $\Delta \bar{k}$ from WindEEE PIV and Cobra probe at M6 for (a) RC1 and (b) RC2 cases.

ment for the uniform fan speed cases, whereas for the shear case, lower roughness caused a slight reduction in speed-up, particularly near the surface. Slightly higher values of speedup were observed for the $1: 25$ scale model compared to the $1: 100$ model, which are attributed to factors such as proximity of the instrument to the model surface or model surface roughness.

From the turbulent flow field data represented in the form of a TKE increment, a weak Reynolds number dependence was observed whereby TKE increased with an increase in the Reynolds number, but only in the highly turbulent shear layer near the escarpment. Lower inflow roughness also served to moderately increase peak TKE among the uniform fan speed cases. A much more significant TKE increase was observed for the shear profile case, where peak normalized TKE at a height of $2 \mathrm{~m}$ above the hill increased by over $200 \%$ compared to the uniform fan speed case at a similar Reynolds number. Through modification of the inflow shear profile, the WindEEE facility was able to produce higher TKE increments, which were closer to full-scale measurements than those that had been achieved previously in conventional wind tunnels, indicating a promising trend for future work in characterizing flow over topography.

For the wind developer, these results reinforce the need for very careful and detailed assessment of wind turbine inflow conditions in complex topography, as even very small changes to the inflow profile used in the modelling process can cause highly significant changes at turbine height, particularly in the turbulent flow behaviour.

\section{Data availability}

The intention is to publish the data used in this paper for public use on a server in the near future. In the meantime, data can be obtained by contacting the authors.

Acknowledgements. The present work is supported by NSERC, CFI, and UWO, in addition to the Center for Computational Wind Turbine Aerodynamics and Atmospheric Turbulence funded by the Danish Council for Strategic Research, grant number 09-067216.

Edited by: J. Lundquist

Reviewed by: A. Cuerva and one anonymous referee

\section{References}

Akomah, A., Hangan, H., and Naughton, J.: Very high Reynolds number boundary layers over 3D sparse roughness and obstacles: the mean flow, Exp. Fluids, 51, 743-752, doi:10.1007/s00348011-1086-2, 2011.

Ayotte, K. W.: Computational modelling for wind energy assessment, J. Wind Eng. Ind. Aerod., 96, 1571-1590, doi:10.1016/j.jweia.2008.02.002, 2008.

Ayotte, K. W. and Hughes, D. E.: Observations of boundarylayer wind-tunnel flow over isolated ridges of varying steepness and roughness, Bound.-Lay. Meteorol., 112, 525-556, doi:10.1023/B:BOUN.0000030663.13477.51, 2004.

Ayotte, K. W., Sullivan, P. P., and Patton, E. G.: LES and wind tunnel modelling over hills varying steepness and roughness, Fifth International Symposium on Computational Wind Engineering (CWE2010), 23-27 May 2010, Chapel Hill, North Carolina, USA, 2010.

Bechmann, A., Sørensen, N. N., Berg, J., Mann, J., and Réthoré, P.-E.: The Bolund experiment, part II: blind comparison of microscale flow models, Bound.-Lay. Meteorol., 141, 245-271, doi:10.1007/s10546-011-9637-x, 2011.

Berg, J., Mann, J., Bechmann, A., Courtney, M. S., and Jørgenson, H. E.: The Bolund experiment, Part I: Flow over a steep, three-dimensional hill, Bound.-Lay. Meteorol., 141, 219-243, doi:10.1007/s10546-011-9636-y, 2011.

Botta, G., Cavaliere, M., Viani, S., and Pospíšil, S.: Effects of hostile terrains on wind turbine performances and loads: The Acqua Spruzza experience, J. Wind Eng. Ind. Aerod., 74-76, 419-431, doi:10.1016/S0167-6105(98)00038-5, 1998.

Bowen, A. J.: Modelling of strong wind flows over complex terrain at small geometric scales, J. Wind Eng. Ind. Aerod., 91, 18591871, doi:10.1016/j.jweia.2003.09.029, 2003.

Chock, G. and Cochran, L.: Modeling of wind speed effects in Hawaii, J. Wind Eng. Ind. Aerod., 93, 623-638, doi:10.1016/j.jweia.2005.06.002, 2005.

Conan, B., Chaudhari, A., Aubrun, S., van Beeck, J., Hämäläinen, J., and Hellsten, A.: Experimental and numerical modelling of flow over complex terrain: the Bolund Hill, Bound.-Lay. Meteorol., 158, 183-208, doi:10.1007/s10546-015-0082-0, 2016.

Diebold, M., Higgins, C., Fang, J., Bechmann, A., and Parlange, M. B.: Flow over hills: a large-eddy simulation of the Bolund case, Bound.-Lay. Meteorol., 148, 177-194, doi:10.1007/s10546-013-9807-0, 2013. 
Hangan, H.: The Wind Engineering Energy and Environment (WindEEE) dome at Western University, Canada, Wind Engineers, JAWE, 39, 350-351, doi:10.5359/jawe.39.350, 2014.

Lange, J., Mann J., Angelou, N., Berg, J., Sjoholm, M., and Mikkelsen, T.: Variations of the wake height over the Bolund escarpment measured by a scanning Lidar, Bound.-Lay. Meteorol., 159, 147-159, doi:10.1007/s10546-015-0107-8, 2016a.

Lange, J., Mann, J., Berg, J., Parvu, D., Kilpatrick, R., Costache, A., Chowdhury, J., Siddiqui, K., and Hangan, H.: For wind turbines in complex terrain, the devil is in the detail, Nature Energy, resubmitted, $2016 \mathrm{~b}$.

Lim, H. C., Castro, I. P., and Hoxey, R. P.: Bluff bodies in deep turbulent boundary layers: Reynolds-number issues, J. Fluid Mech., 571, 97-118, doi:10.1017/S0022112006003223, 2007.

Ly, L. N.: Effect of the angle between wind stress and wind velocity vectors on the aerodynamic drag coefficient at the air-sea interface, J. Phys. Oceanogr., 23, 159-163, doi:10.1175/15200485(1993)023<0159:EOTABW>2.0.CO;2, 1993.

Manwell, J. F., McGowan, J. G., and Rogers, A. L.: Wind energy explained, 2nd Edn., John Wiley \& Sons Ltd., Chichester, West Sussex, UK, 2009.

McAuliffe, B. R. and Larose, G. L.: Reynolds-number and surfacemodeling sensitivities for experimental simulation of flow over complex topography, J. Wind Eng. Ind. Aerod., 104-106, 603613, doi:10.1016/j.jweia.2012.03.016, 2012.

Palma, J. M. L. M., Castro, F. A., Ribeiro, L. F., Rodrigues, A. H., and Pinto, A. P.: Linear and nonlinear models in wind resource assessment and wind turbine micro-siting in complex terrain, J. Wind Eng. Ind. Aerod., 96, 2308-2326, doi:10.1016/j.jweia.2008.03.012, 2008.

Peinke, J., Barth, S., Böttcher, F., Heinemann, D., and Lange, B.: Turbulence, a challenging problem for wind energy, Physica A, 338, 187-193, doi:10.1016/j.physa.2004.02.040, 2004.
Rasouli, A., and Hangan, H.: Micro-scale CFD simulation for wind mapping over complex topographic terrains, J. Sol. Energ.T. ASME, 135, 041005, doi:10.1115/1.4024124, 2013.

Rasouli, A., Hangan, H., and Siddiqui, K.: PIV measurements for complex topographic terrain, J. Wind Eng. Ind. Aerod., 97, 242254, doi:10.1016/j.jweia.2009.06.010, 2009.

Salmon, J. R., Teunissen, H. W., Mickle, R. E., and Taylor, P. A.: The Kettles Hill project: field observations, wind-tunnel simulations and numerical model predictions for flow over a low hill, Bound.-Lay. Meteorol., 43, 309-343, doi:10.1007/BF00121711, 1988.

Siddiqui, K., Loewen, M. R., Richardson, C., Asher, W. E., and Jessup, A. T.: Simultaneous particle image velocimetry and infrared imagery of microscale breaking waves, Phys. Fluids, 13, 1891903, doi:10.1063/1.1375144, 2001.

Taylor, P. A. and Teunissen, H. W.: The Askervein Hill project: overview and background data, Bound.-Lay. Meteorol., 39, 1539, doi:10.1007/BF00121863, 1987.

Tritton, D. J.: Physical Fluid Dynamics, Van Nostrand Reinhold Co., New York 1977.

Walmsley, J. L. and Taylor, P. A.: Boundary-layer flow over topography: impacts of the Askervein study, Bound.-Lay. Meteorol., 78, 291-320, doi:10.1007/BF00120939, 1996.

Weber, R. O.: Remarks on the definition and estimation of friction velocity, Bound.-Lay. Meteorol., 93, 197-209, doi:10.1023/A:1002043826623, 1999.

Yeow, T. S., Cuerva-Tejero, A., and Perez-Alvarez, J.: Reproducing the Bolund experiment in wind tunnel, Wind Energy, 18, 153169, doi:10.1002/we.1688, 2015. 